\title{
REDES NACIONAIS DE INFLUÊNCIA EM POLITICAS EDUCACIONAIS
}

Edgar Miranda

Colégio Pedro II

Rita Vilanova

Universidade Federal do Rio de Janeiro - UFRJ

\section{Resumo}

No contexto da reforma do estado de provisão social, redes de influência de políticas têm buscado a reorientação da lógica administrativa da educação pública, mercantilizando-a e constrangendo-a para atender às demandas do mercado. Com base nesse entendimento, esta pesquisa buscou compreender a organização, as estratégias e os artefatos utilizados por grupos de influência para promover mudanças nas atuais políticas educacionais. Identificou-se também os discursos e formas narrativas mobilizados para difundir, em nível nacional, a educação neoliberal. Em face de tal propósito, mapeou-se as ramificações no Brasil de uma dessas redes de influência, a Atlas Liberty Network. Optou-se por focar a análise nas conexões entre instituições e relações dos sujeitos a ela afiliados. Os resultados apontaram as formas de organização, a extensa conectividade e a inserção política de rede tal rede nas políticas educacionais, com destaque para o grande protagonismo dos movimentos Todos pela Educação e Movimento pela Base. Quanto à utilização por essa rede dos discursos, mecanismos, artefatos e formas de influência políticas, destaca-se a proposta de implantação de uma cultura de performatividade/meritocracia e a busca pela privatização/terceirização da educação por meio do sistema vouchers.

Palavras-chave: políticas educacionais; redes de influência; think tanks.

\begin{abstract}
In the context of the Welfare State reform, political pressure groups have been seeking to reorganize administration's logic of public education, by marketizing it and constraining it to meet the demands of the private markets. According to this view, the present research sought to understand the organization, strategies and artifacts used by these political pressure groups to change current educational policies. Also, we identify the political rhetoric mobilized to translate, at the national level, the neoliberalization of education. In this regard, we mapped the national ramifications of Atlas Liberty Network, one of these political pressure groups and searched for connections between institutions and the dynamic of relationships among its members. The results point to the organization methods, the wide network acitivity, and its political permeability among educational policies, with Todos pela Educação and the Movimento pela Base playing a major role. The analysis of network's discourses, mechanisms, artifacts and forms of influence in public policies highlights the proposal to apply a performativity/meritocracy logic and the search for privatization/outsourcing of education through the vouchers system.
\end{abstract}

Keywords: educational policies, political pressure groups, think thanks.

ISSN 1645-1384 (online) www.curriculosemfronteiras.org 


\section{Introdução}

No contexto da reforma do estado de provisão social, a relação interdependente entre Estado, Mercado e Sociedade têm sido redesenhada de forma complexa, com o objetivo de reorganizar tais esferas dentro de um modelo de base político-econômica neoliberal (HARVEY, 2005; 2014; BALL, 2014; AVELLAR; BALL, 2017; AVELAR; NIKITA; BALL, 2018).

Os fundamentos político-econômicos desse empreendimento, alicerçados nos princípios do liberalismo clássico e do libertarianismo ${ }^{1}$, defendem a redução da intervenção social do Estado por meio da desregulação e privatização de suas ações, bem como o desmantelamento dos serviços de provisão social e sua respectiva substituição por atividades de mercado. Afinal, para o neoliberalismo, a liberdade de iniciativa empresarial dos indivíduos seria "la mejor manera de promover el bienestar del ser humano(...) dentro de un marco institucional caracterizado por derechos de propiedad privada fuertes, mercados libres y libertad de comercio" (HARVEY, 2005, p. 6).

Ao mesmo tempo em que o discurso neoliberal acusa o Estado de paternalismo, por subsidiar o atendimento social da população, há um forte esforço de cooptação dos recursos financeiros dessas mesmas áreas, a fỉm de construir novas formas e espaços de exploração do capital. O Estado assume, dessa forma, a função adicional de promover condições para que sejam viabilizados negócios financeiros. Verifica-se, portanto, a incoerência entre a práxis neoliberal e o seu discurso político.

De acordo com Harvey (2005) e Ball (2014), tal perspectiva coloca o Estado enquanto agente do mercado e cria espaços de comercialização em áreas em que "no existe mercado (como la tierra, el agua, la educación, la atención sanitaria, la seguridad social o la contaminación medioambiental)" (HARVEY, 2005, p. 6 -7).

Nesse contexto, a privatização do setor educacional vem sendo articulada em diferentes países por meio de processos sofisticados de mudança na cultura organizacional da administração pública (BALL, 2011). Alguns desses processos envolvem movimentos de privatização mais perceptíveis, com a constituição de parcerias público-privadas ou com a abertura de setores educacionais ao capital privado. Um exemplo possível desse mecanismo é a fusão da Somos Educação com a Kroton ${ }^{2,3}$, que passa a ser a maior empresa de educação do país, controlando as principais editoras de livros didáticos e especializados (Editora Ática, Scipione, Saraiva, Atual, Saraiva Universitária e Saraiva Jurídica) e captando grande parte dos subsídios públicos do Programa Nacional do Livro Didático (PNLD) (KENJI, 2018).

Já outros processos de privatização atuam de forma endógena, operando por meio de instrumentos sofisticados e quase imperceptíveis, o que dificulta a sua detecção. Isso porque atuam dentro e a partir da recriação das formas de controle e de organização de setores públicos. Em consequência, a educação pública assume novos princípios e discursos de cunho mercadológico, passa a atuar sob uma perspectiva instrumental e pragmática e a ser pensada por critérios de impacto, eficiência, desempenho e competitividade.

No caso brasileiro, observando as tentativas de reforma do sistema educacional em uma perspectiva temporal ampla, vem sendo apontada, desde as mudanças curriculares dos anos 
1990, a tentativa de articulação de discursos que buscam deslocar sentidos e ideias das políticas educacionais, promovendo o alinhamento de seus objetivos com as ideias de mercado (MARTINS, 2016; FREITAS, 2018; SILVA JÚNIOR, 2002). Destacam-se a constituição de discursos em torno da qualidade da educação (MACEDO, 2009; BAUTHENEY, 2014), das competências/direitos/expectativas de aprendizagem (MACEDO, 2015) e da cultura de meritocracia/performatividade (MOREIRA, 2009; LOPES; LÓPEZ, 2010; HATTGE, 2014; ESQUINSANI, 2010; LEITE, 2014; PACHECO; PESTANA, 2014).

De acordo com Bautheney (2014), o discurso da qualidade da educação vem sendo associado aos resultados de avaliações padronizadas, que têm como base os conteúdos tradicionais, ou de "cunho universal" (MACEDO, 2009, p. 93). Bautheney (2014) aponta que a noção de qualidade da educação é definida pelo desempenho dos alunos nesses exames, constituídos a partir das demandas do mercado, como é o caso do Programa Internacional de Avaliação dos Estudantes (PISA).

A performatividade é colocada por Ball $(2002,2004,2005)$ como um mecanismo de regulação social e moral, sendo explorado e reconhecido por um amplo espectro de pesquisas educacionais (MOREIRA, 2009; LOPES; LÓPEZ, 2010; HATTGE, 2014; ESQUINSANI, 2010; LEITE, 2014; PACHECO; PESTANA, 2014). Segundo Ball (2014), o conceito consiste não só em um sistema de desempenho, mas em uma "tecnologia moral" do neoliberalismo, que atua em dimensões subjetivas que conduz e incita os sujeitos a se tornarem mais produtivos (mas sem profundidade), colocando-se em um processo constante de aperfeiçoamento do eu, sentindo-se culpados ou inadequados pelas metas não atingidas: "Ela opera dentro de um arcabouço de julgamento no qual a definição de "aperfeiçoamento" e de eficácia é determinada por nós e "indicada" por medidas de qualidade e produtividade" (BALL, 2014, p. 66).

Esse mecanismo tem tensionado a noção de avaliação e acompanhamento da aprendizagem dos alunos, tentando ressignificar e constranger seus sentidos, de forma que se ajuste à perspectiva de gerenciamento de recursos humanos para o mercado. Ao longo da reforma do sistema educacional brasileiro, vários critérios de acompanhamento da aprendizagem dos alunos foram propostos, a saber; os saberes/conhecimentos (conceituais, comportamentais e atitudinais) e; os objetivos/competências/expectativas/direitos de aprendizagem.

A apropriação e a difusão das competências no campo educacional, sobretudo com o trabalho de Perrenoud (1999), representaram para muitos educadores a incorporação de um mecanismo neoliberal de gestão de pessoas para o mercado. Isso porque esse sistema de gerenciamento foi incorporado inicialmente pelo mundo do trabalho, sendo reatualizado em substituição à gestão taylorista por objetivos.

Com isso novas disputas ocorrem em torno dos objetos da educação, nas quais visões de mundo concorrem para significar seus sentidos e conformar perspectivas que tensionamse/hibridizam-se entre categorias conflitantes, como "competição x solidariedade, premiação x justiça social, lógica do mercado competitivo x lógica dos direitos sociais" (BURNIER, 2001). 
Essa reorientação da gestão ocorre, sobretudo, via mudanças na legislação educacional, que passa a incorporar novas formas de olhar, organizar e gerenciar a educação pública e permite que Redes Transnacionais de Influência (TAN) atuem discursivamente pressionando, influenciando e ressignificando os objetos e os espaços de que tratam as políticas públicas, deslocando-os e os preenchendo com significados outros que orientam a ação e a interação social dos sujeitos. As TANS consistem em redes que compõe estruturas comunicativas que, caracteristicamente, buscam promover princípios, ideias e valores partilhados pelos seus membros (BALL, 2014).

É nesse sentido que Verger, Novelli e Altinyelken (2018, p.7) consideram que "[...] as políticas públicas são hoje o resultado de uma combinação de forças políticas, estruturas sociais, tradições culturais e processos econômicos enredados em uma matriz de intersecção multinível, multiescalar" [...] (tradução nossa ${ }^{4}$ ).

Nesse processo, destaca-se a atuação das think tanks - TT que, por meio de uma organização composta por atores coletivos (como ONGs e grupos privados) e individuais (como consultores políticos e empreendedores sociais), possibilitam a capilarização e a circulação das ideias neoliberais nos sistemas políticos, com a constituição de "teias de relações" e interações de rede (BALL, 2014). De acordo com Teixeira (2007, p. 81), essas organizações atuam dentro dos sistemas democráticos como atores políticos formidáveis, exercendo influência a partir da construção de verdades e construindo pontes entre "o conhecimento e as ideias políticas".

A atuação complexa e opaca dos atores coletivos e individuais pontua a necessidade de compreensão das formas de atuação e dos processos materiais, simbólicos e intelectuais que tais redes de influência política utilizam para dar mobilidade e capacidade de expansão às ideias neoliberais (BALL, 2014).

Sendo assim, a presente investigação busca compreender a organização, os discursos e artefatos de grupos de influência política que têm investido em mudanças nas atuais políticas educacionais brasileiras. O objetivo é entender o "sistema circulatório" desses grupos e, a partir de sua capilaridade, refletir também sobre a contribuição de suas ideias e discursos para o fim da educação pública enquanto política de "bem-estar" (BALL, 2014).

Para isso, realizamos um mapeamento das ramificações nacionais de uma dessas redes de influência, a Atlas Liberty Network. Ao longo do texto, apresentamos a concepção teórica do conceito de rede e de seu papel para mobilidade de discursos e das políticas neoliberais. Destacamos também os procedimentos do mapeamento e os resultados principais, que apontam a mobilização política de organizações financeiras, atores e instituições públicas e privadas para influenciar as políticas educacionais brasileiras. Por fim, realizamos nossas considerações finais, discutindo os impactos dessas influências na configuração/relação do Estado e do Mercado para a educação e para a própria democracia. 


\section{Redes enquanto dispositivo teórico-metodológico}

O conceito de Rede é aqui trabalhado como um dispositivo teórico-analítico que busca compreender os processos de influência política dentro dos contextos de produção de políticas públicas (BOWE; BALL, 1992) e também como um "tecido conectivo" que liga e dá organicidade às comunidades políticas da atualidade, constituindo-se como um novo social (BALL, 2014). Essa última acepção encontra sentido a partir da noção de atuação da política enquanto um processo contínuo e criativo, na qual seus textos são (re)construídos pelos sujeitos a partir da sua recontextualização nos diferentes espaços de sua abrangência (MAINARDES, 2006).

Ball (1998) reconhece a resultante da migração e acomodação de textos/discursos em outros contextos como "híbridos culturais" (OLIVEIRA; LOPES, 2011; LOPES; CUNHA; COSTA, 2013), constituídos por meio de uma "bricolagem", com o empréstimo e cópia de "pedaços de ideias de outros lugares" (BALL, 1998, p. 126).

Ball, Maguire e Braun (2012), ancorando-se na proposta da análise crítica do discurso de Fairclough (2003), assumem que textos e enunciados são moldados por textos anteriores, entendendo a "propriedade que tem os textos de ser cheios de fragmentos de outros textos, que podem ser delimitados explicitamente ou mesclados" (FAIRCLOUGH, 2001, p. 114).

Esses elementos podem ser percebidos pelas diferentes formas de apropriação e representação, como a "presença explícita de outros textos em um texto" (FAIRCLOUGH, 2001, p. 29), ou por nuances linguísticas que constroem núcleos de sentindo que possibilitam perceber suas posições frente ao "discurso do outro" (RESENDE; RAMALHO, 2017). Isso porque, o discurso corresponde a um "modo particular de representar parte do mundo", ou seja, uma forma de simbolizar, caracterizar e qualificar o mundo material/mental e seus aspectos conforme diferentes perspectivas/posições (FAIRCLOUGH, 2003, p. 26).

Durante o processo de formação de discursos e da legitimação dos sentidos da política, percebe-se diversos grupos de interesse construindo tais sentidos em torno de políticas locais e também representando pensamentos e ideias de comunidades políticas globais e internacionais (BALL, 2014; AVELLAR; BALL, 2017; 2018; PERONI; SCHEIBE, 2017; PERONI; CAETANO; LIMA, 2017; BERNARDI; BOROWSKY; MONTANO; SUSIN, 2017). Esses grupos tomam de empréstimo propostas político-econômicas internacionais e de agências de financiamento a fim de aplicá-las na política educacional (MAINARDES, 2006).

Atores individuais e coletivos, associados em favor da reforma neoliberal da educação, passam a constituir redes transnacionais e heterogêneas de influência, promovendo a circulação de seus discursos dentro da arquitetura social e estatal. O poder de influência das redes na esfera estatal tem relação com sua constituição diversificada, que envolve organizações não-governamentais, grupos privados, consultores políticos, governos nacionais, think tanks, empreendedores sociais, empresas internacionais e agências multilaterais. Entre as últimas destacam-se o Banco Interamericano de Desenvolvimento (BID), o Fundo Monetário Internacional (FMI), o Banco Mundial (BM), a Organização 
Mundial do Comércio (OMC), a Organização para Cooperação e Desenvolvimento Econômico (OCDE), a UNESCO, entre outras (BALL, 2014).

Em grande parte, o processo de influência das redes se dá pela via discursiva, a partir da constituição de narrativas que legitimam e reforçam a necessidade de reforma da educação. De acordo com Ball (2014, p. 120):

Ideias de políticas não se movem no vácuo, elas são criações sociais e políticas que são contadas e recontadas em micro-espaços de políticas. [...] Esses microespaços de políticas são configurações preeminentes e eventos de falas e de trocas onde a confiança é construída, e os compromissos e os negócios são feitos.

Oportunamente, as TANs, sob alegação que o Estado fracassa em atender áreas sociais como a educação, têm proposto soluções rápidas e baratas, quase "mágicas" (BALL, 2011), a partir da ressignificação das ações públicas e da metaorganização da cultura organizacional por meio de linhas gerencialistas/empreendedoras, baseadas na lógica organizacional empresarial (BALL, 2011; 2014) e em uma racionalidade econômica que desconsidera arbitrariamente as questões éticas de bem-estar geral, concentrando seus esforços no crescimento econômico (SEN, 2012).

Esse seria o princípio ético que guiaria a atividade educativa, com "penetrantes efectos en los modos de pensamiento, hasta el punto de que ha llegado a incorporarse a la forma natural en que muchos de nosotros interpretamos, vivimos y entendemos el mundo" (HARVEY, 2005, p. 7). O processo de influência, portanto, passa a ser entendido como campo de disputas de ideias.

Entretanto, para que a forma de pensar dessas redes alcance os diferentes contextos da vida e da produção das políticas públicas, é necessário que seu discurso tenha eco nos contextos de atuação da política, com aceitação e adesão das instituições e dos atores políticos (BALL; MAGUIRE; BRAUN, 2012). Nesse sentido, a atividade político-epistêmica das think tanks tem grande centralidade, exercendo poder simbólico de significação e legitimação das propostas políticas.

A multiplicidade, o hibridismo e a multimodalidade de ações desenvolvidas por essas organizações têm oferecido dificuldades para sua definição teórica, estando, muitas vezes, localizadas nas fronteiras de outras caracterizações (como grupos de influência, intelligentsia, comunidades epistêmicas, entre outros). Logo, essa imprecisão afasta o termo de um centro consensual.

Contudo, a atuação desses atores políticos permite identificar certos padrões em sua constituição. A grande maioria se define como "organizações relativamente independentes, não-partidárias, sem fins lucrativos", tendo como atividade-fim a produção de conhecimento, cujos objetivos seriam "resolver problemas, desenvolver projetos de curto, médio e longo prazos, e realizar pesquisas, sobretudo, nas áreas de políticas públicas [...]" (TEIXEIRA, 2007, p. 105).

Na prática, entretanto, a realidade é outra, pois são poucas as organizações que mantêm de forma desinteressada o princípio pedagógico de sua gênese, a saber: "desenvolver 
conhecimento científico nos problemas políticos e fazer pesquisas acadêmicas de alto padrão para ajudar a educar e informar os políticos e o público" (TEIXEIRA, 2007, p.131). Há também relações declaradas com entidades e partidos políticos, aos quais é fornecido apoio intelectual.

As think tanks adicionam aos mecanismos discursivos dessa rede uma teia multidimensional de "relações para a difusão do conhecimento e da informação" (BALL, 2014, p. 39), e lhe concedem caráter "científico" (TEIXEIRA, 2007), proporcionando assim voz e influência nos processos decisórios políticos.

Enquanto "reservatórios de ideias", as think tanks atuam como conselheiras do Estado, tentando inculcar nos atores políticos determinada perspectiva de educação e de mundo (TEIXEIRA, 2007). De acordo com Teixeira (2007, p. 84-85), “o tentáculo das ideias destas instituições é tão poderoso que consegue construir, por meio da coerção pela razão, uma cadeia simbólica que explica uma dada realidade, formulando verdades que, associadas a certos mecanismos e fatores de poder, justificam todo um projeto [político]”.

$\mathrm{Na}$ disputa entre ideias, essas organizações, por intermédio de diversificadas estratégias de empreendedorismo e de mobilização da opinião, têm conseguido circular discursos que legitimam e reforçam a reforma neoliberal a partir da privatização da educação. No caso, é perceptível uma mudança de sentido e de significado dos objetos e quadros educacionais que redefinem os papéis, a lógica e a subjetividade dos atores educacionais (BALL et. al., 2013). Ball (2011) e Maguire e Ball (2011) relacionam alguns dos mecanismos e termos-chave que têm reorientado o gerenciamento e a forma de ver a educação. Entre eles destacam-se a prescrição da organização centrada nas pessoas, a definição dos pensamentos e sentimentos dos empregados sobre o que produzem, a responsabilização individual pela eficiência, a competição e comparação interpessoal de performances.

Esses seriam alguns dos "novos conceitos e expressões" que buscam "deter o domínio do simbólico e interferir na realidade" (TEIXEIRA, 2007, p. 30), articulando nas políticas públicas o discurso de neoliberalização da educação. Na pesquisa proposta, buscamos identificar grupos que têm procurado influenciar as políticas educacionais brasileiras ao longo das últimas décadas, destacando as ações, discursos e estratégias utilizadas para traduzir na legislação educacional mecanismos da reforma neoliberal. Isso porque entendemos que os discursos neoliberais circulam em um nível de estrutura macrossocial, precisando de um processo de tradução em propostas objetivas para áreas sociais como a educação.

Diante do exposto, focamos nossa investigação na atuação da Atlas Liberty Network dentro do Brasil, buscando destacar as relações e a influência dessa rede nas políticas públicas nacionais.

\section{Metodologia}

Para compreender a rede de influência transnacional da Atlas Liberty Network no país, procedemos com uma análise em rede, entendida como um dispositivo analítico que pode 
representar "a estrutura das comunidades políticas" e as "relações sociais" que a compõe (AVELLAR; NIKITA, BALL, 2018, p. 57; BALL, 2014).

A proposta foi operacionalizada por meio de uma etnografia de rede (BALL; JUNEMAN, 2012, p. 13; BALL, 2016; AVELLAR; NIKITA, BALL, 2018) que consiste na imersão na rede, combinando criteriosamente ferramentas da etnografia de campo, como observação, entrevistas e análise de textos. Esses procedimentos buscam fornecer uma "topografia da rede de políticas" (BALL, 2016) a partir do mapeamento das relações entre os atores sociais, políticos e econômicos e as ideias que compartilham e os mobilizam (VERGER; STEINER-KHAMSI; LUBIENSKIC, 2017).

Em termos gerais, a etnografia de rede aborda 'as pessoas, lugares e momentos' (Prince 2010) envolvidos na elaboração e reformulação de políticas móveis e tenta identificar os caminhos e pipelines, nós e atividades pelas quais a política se move [...] (BALL, 2016, p. 4, tradução nossa ${ }^{5}$ )

Para sistematizar os processos, desenvolvemos a pesquisa em três etapas, conforme a perspectiva da etnografia de rede apresenta por Ball e Junemann (2012). Dessa forma, em um primeiro momento, realizamos buscas sistemáticas e extensas na internet, tomando a Atlas como ponto partida, dada sua influência (in)direta na produção de políticas públicas. No caso, buscamos identificar as associações institucionais e pessoais de atores e organizações brasileiras. Para isso acessamos informações, dados e materiais públicos disponibilizados nos websites das entidades, em perfis em redes sociais (Facebook, Twitter e Linkedin), blogs, podcasts, nos currículos profissionais (Plataforma Lattes), em eventos, publicações etc.

Esses dados foram processados por meio da plataforma $\mathrm{ONODO}^{6}$, que indicou os nós da rede (instituições e coletivos identificados) e possibilitou identificar a topografia do cluster, ou seja, o mapa do aglomerado de nós conectados pelos links da rede (BARABÁSI, 2009, p. 15).

Entretanto, concordamos com Ball (2014) e Shiroma (2014), em reconhecer a importância dos atores individuais na construção links, cuja análise pode indicar a densidade, a frequência e aspectos mais específicos dos vínculos estabelecidos.

Dessa forma, conectamos os sujeitos afiliados as instituições, compondo sociogramas que representam graficamente os vínculos, conectividades, capilarização e inserção dos atores em diferentes contextos e setores sociais, com ênfase nos setores públicos.

Em um segundo momento da pesquisa, buscamos apreender as ideias e os discursos que vinculam e mobilizam a rede na tentativa de influenciar a política educacional, traduzindo nela a mentalidade neoliberal. Nesta parte foram analisados documentos, publicações, entrevistas e palestras dos indivíduos identificados na busca online. Além disso, participamos e observamos eventos promovidos pela rede.

Os eventos de fala e as publicações foram analisados, entendendo-os como "híbridos culturais" (OLIVEIRA; LOPES, 2011; LOPES; CUNHA; COSTA, 2013), nos quais 
buscamos identificar fragmentos e nuances linguísticas que, enquanto núcleos de sentindo, representam a apropriação de discursos ou textos (FAIRCLOUGH, 2001).

Os dados dessas etapas foram reunidos em duas categorias, nomeadamente: (i) "Redes de influência das políticas públicas educacionais: organização, conectividade e inserção política" e (ii) "Discursos, mecanismos, artefatos e formas de influência as políticas". Estas são discutidas na sequência do texto. Antes apresentamos alguns dados que dimensionam a potência de influência política da Atlas Liberty Network.

\section{Os entrelaçamentos da rede Atlas Liberty network na América Latina e no Brasil}

Como foi destacado, as redes políticas reúnem um número diversificado de instituições. Sua extensão, que não se situa em um setor social específico, dificulta identificar um ponto nodal ou retratar toda a sua teia conjuntiva. Diante disso, tomou-se por referência os apontamentos das pesquisas sobre a Atlas Economic Research Foundation (BALL, 2014), concentrando-se em suas ramificações no Brasil a partir da rede Atlas Liberty Network.

A Atlas Liberty Network constitui-se como uma meta-think tank que atua como um nódulo da rede, articulando, promovendo e financiando a circulação e a reiteração de "publicações, de ideias, de defesa do mercado livre, de políticas libertárias sociais e econômicas" (BALL, 2014, p. 55). De acordo com informações de seu site, a Atlas Network se conecta a uma rede global composta por mais de 475 organizações de livre mercado em cerca de 100 países, com as quais mantém um fluxo constante de ideias e recursos financeiros para promover a causa da liberdade. A extensão dessa rede pode ser ainda maior, pois não se encontram relacionadas as conexões informais e indiretas dessa instituição.

Essa think tank tem parcerias político-econômicas importantes com os fundadores do movimento neoliberal, tais como a Mont Pelerin Society ${ }^{7}$. Friedrich Haeyk foi um dos seus membros e está entre suas ideias fonte de inspiração (BALL, 2014). A Atlas também mantém relações políticas e financeiras com a família Koch, sendo que um de seus ex-presidentes, John Blundell (1952 - 2014), foi diretor da Charles Koch Foundation.

Essas relações delimitam um pequeno nicho na ampla cadeia de circulação de ideias e de financiamento que representa a rede, a qual se estende pelo setor educacional. Por exemplo, a Charles Koch Foundation financia cerca de 300 universidades americanas por meio da Fred and Mary Koch Foundation. Essas ações, entretanto, não se dão em um vácuo ou de forma desinteressada. A pesquisa de MacLean (2017) aponta que esses financiamentos servem para que os irmãos Charles e David Koch (como também outros bilionários) promovam um projeto político que busca o fim do serviço público e do Estado de bemcomum.

$\mathrm{Na}$ América Latina e no Caribe, a Atlas ${ }^{8}$ relaciona 78 instituições, com as quais mantém parceria, cujos nomes são listados abaixo: 
- Argentina: Centro para la Apertura y el Desarrollo de América Latina; Fundación Atlas 1853; Fundación Bases; Fundación Federalismo y Libertad; Fundación Instituto David Hume; Fundación Libertad; Fundación para la Responsabilidad Intelectual; Instituto Acton; Libertad y Progreso;

- Chile: Centro de Estudios Públicos; Centro de Investigación de la Empresa; Circulo Acton Chile; Ciudadano Austral; Fundación Chile Intercultural; Fundación Leadership Institute Chile; Fundación P!ENSA; Fundación para el Progreso; Instituto de Estudios de la Sociedad; Instituto Res Publica; Libertad y Desarrollo;

- Costa Rica: Asociación Nacional de Consumidores Libres; Asociación Nacional de Fomento Económico; Democracy Lab; Instituto de Desarrollo Empresarial y Acción Social;

- México: Caminos de La Libertad; Instituto de Pensamiento Estratégico Agora A.C. Agora Institute For Strategic Thinking; Instituto Mexicano para la Competitividad; México Evalúa;

- Jamaica: Caribbean Policy Research Institute;

- Venezuela: Centro de Divulgación del Conocimiento Económico para la Libertad CEDICE; Econintech; Forma, Formación y Acción; Liderazgo y Visión, A.C.;

- Uruguai: Centro de Economía, Sociedad y Empresa - ESSE; Centro de Estudios de la Realidad Económica y social; Centro de Estudios para el Desarrollo;

- Bolívia: Centro de Estúdios de la Realidad Económica y social - CERES; Fundación Nueva Democracia; Instituto de Ciencia, Economía, Educación y Salud; Libera Bolivia; Políticas Publicas Para la Libertad;

- Guatemala: Centro de Estudios Económico-sociales; Centro de Investigaciones Económicas Nacionales; Instituto Fe y Libertad; Universidad Francisco Marroquín;

- República Dominicana: Centro Regional de Estrategias Económicas Sostenibles; Instituto Especializado de Investigación y Formación en Ciencias Jurídicas;

- Peru: Contribuyentes por Respeto; Democracia y Desarrollo; Hiperderecho; Instituto Libertad y Democracia; Instituto Peruano de Economía; Instituto Político para la Libertad; Latin American and Iberian Law and Economics Association;

- El Salvador: CREO; Fundación Salvadoreña para el Desarrollo Económico y social;

- Equador: Dollarization and Banking Institute; Instituto Ecuatoriano de Economia Politica; Think Tank Ecuador;

- Honduras: Fundación Eleutera;

- Panamá: Fundación Libertad (Panamá); Instituto de Estudios para una Sociedad Abierta;

- Colômbia: Instituto de Ciencia Política;

- Bahamas: Nassau Institute.

A Atlas financia ainda a "Estudiantes por la Libertad", que se apresenta como uma organização de estudantes pró-liberdade, a qual busca a formação de uma nova geração de 
líderes que possam produzir mudanças em suas comunidades. Esse grupo atua em toda a América Latina.

O Brasil, especificamente, é o país latino-americano com o maior número de think tanks listadas como parceiras pela Atlas, destacando os seguintes grupos: Estudantes pela Liberdade (Belo Horizonte); Instituto Atlantos (Porto Alegre); Instituto de Estudos Empresariais (Porto Alegre); Instituto de Formação de Líderes (Belo Horizonte); Instituto de Formação de Líderes - SP (São Paulo); Instituto Liberal (Rio de Janeiro); Instituto Liberal de São Paulo (São Paulo); Instituto Liberdade (Porto Alegre); Instituto Ludwig von Mises Brasil (São Paulo); Instituto Millenium (Rio de Janeiro); Líderes do Amanhã Institute (Vitória); Mackenzie Center For Economic Freedom (São Paulo); Students for Liberty Brasil (São Paulo).

\section{Redes de influência das políticas públicas educacionais: organização, conectividade e inserção política}

O processamento dos dados pela Plataforma ONODO forneceu um mapa da rede Atlas Liberty Network no Brasil, em que são destacadas as conexões entre as instituições que à compõem e suas ramificações em organizações análogas, como é apresentado na Figura 1: 
Figura 1 - Sujeitos coletivos de influência em políticas educacionais no Brasil.

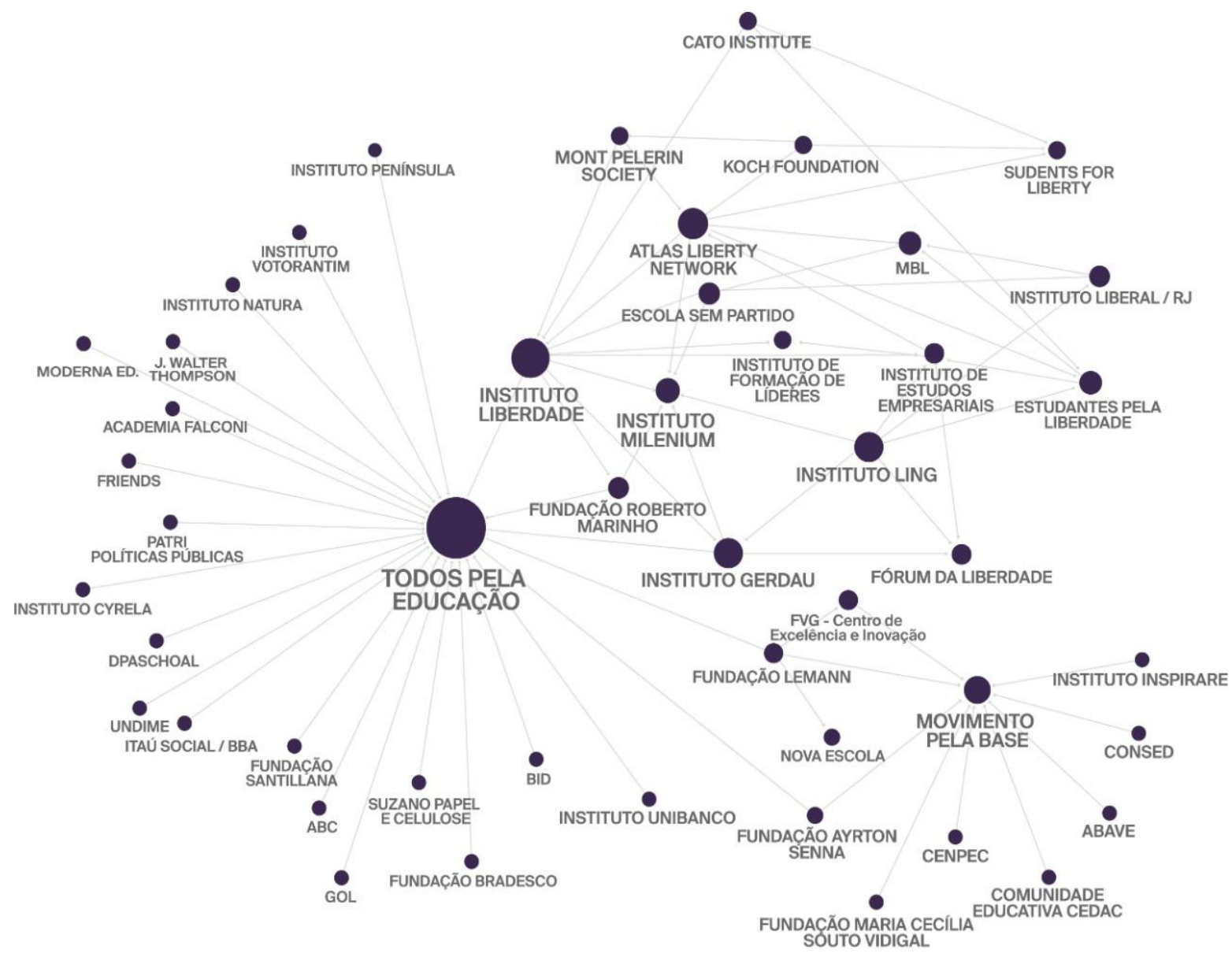

O mapeamento apresentado na Figura 1 representa a topografia de uma parte da rede de conexões que a Atlas tem no Brasil, pois, como citamos, seus integrantes passam a constituir outras associações, capilarizando e encadeando as relações por meio de parcerias e financiamento de programas. Devido a quantidade de links diretos com a Atlas e outras organizações internacionais, tomamos como trajetória inicial na rede, o estudo de seis think tanks, a saber: Instituto Liberal (Rio de Janeiro), Instituto Millenium (Rio de Janeiro), Instituto Liberdade (Porto Alegre), Instituto de Estudos Empresariais (Porto Alegre) e o Students for Liberty). Essas instituições mantêm papel estratégico na ramificação da Atlas, atuando como núcleos multiplicadores de instituições análogas e na formação de líderes (como o Movimento Brasil Livre, criada por ex-integrantes da Students for Liberty Brasil); além de serem as primeiras instituições a integrarem a Network no Brasil.

Ao conectarmos os indivíduos foi possível identificar, também, nós com um número extraordinário de links, nos direcionando ao Movimento Todos pela Educação e o 
Movimento pela Base, que é financiado pela Fundação Lemann e mantém grande poder de influência na produção de políticas educacionais.

Para termos uma noção mais detalhada dessas relações, discutimos essas think tanks de forma particularizada, ressaltando sua inserção social a partir das relações institucionais e pessoais de seus filiados. Neste sentido, são apresentados sociogramas do quadro institucional das think tanks estudadas, bem como das relações individuais de seus integrantes, por meio das quais se estabelece sua capilarização.

Inicialmente, destacamos o Instituto Liberal - RJ, que se expandiu a partir da criação de filiais em todo o país. No caso, são listadas instituições como o Instituto Mises Brasil, os Institutos de Formação de Líderes, o Instituto Millenium, o Instituto Liberal do Nordeste, o Instituto Ordem Livre e o Estudantes pela Liberdade.

Assim como as demais think tanks, o Instituto Liberal se propõe influenciar a organização jurídica, política, econômica e administrativa do Estado a partir de suas pesquisas, produções e divulgação de ideias e teorias. Para isso, ele busca promover a circulação de seus discursos, utilizando-se da mobilidade social de seus integrantes que possuem espaço na mídia, na administração pública e na política.

Por exemplo a atuação de Roberto Gomides - foi superintendente de Captação de Recursos, Assessor-Especial da Secretaria de Fazenda do Estado do Rio de Janeiro e Gerente de Controles Financeiros do Comitê Organizador dos Jogos Olímpicos e Paraolímpicos do Rio 2016 - e de Rodrigo Constantino - atuou como colunista da ISTOÉ, Gazeta do Povo e outros veículos midiáticos, tendo destaque também nas mobilizações pelo impeachment da presidenta eleita Dilma Roussef (organizadas pelo MBL) e cujo apoio aos projetos de lei do Movimento Escola sem Partido (ESP) é público e notório.

Rodrigo Constantino também atua no Instituto Millenium (Imil) ${ }^{9}$, criado em 2005 pela economista Patrícia Carlos de Andrade ${ }^{10}$. Seguindo a tendência da rede, o Imil apresenta-se como uma entidade sem fins lucrativos e sem vinculação político-partidária. A análise do quadro funcional e das relações institucionais do Imil reforça a capacidade de circulação de discursos e de influência dessas instituições. No caso, são apresentados em seu corpo mantenedor o vice-presidente do maior monopólio midiático do Brasil, João Roberto Marinho, bem como Armínio Fraga (ex-presidente do Banco Central), Henrique Meirelles (ex-presidente do Banco Central e ex-ministro da Fazenda) e Paulo Guedes (atual Ministro da Fazenda do governo Bolsonaro). Essas filiações nos dão uma ideia da capacidade de circulação, no setor público, dos discursos político-econômicos neoliberais, com o alinhamento das ações estatais às ideias desse modelo político.

Em nossas análises da rede, destacou-se também a figura de William Ling como um articulador importante das think tanks. A família Ling, no interior da rede, tem sido uma enérgica multiplicadora de think tanks, sendo os irmãos William, Wilson e Winston Ling relacionados como membros de diversas instituições, tal como Instituto Liberal ${ }^{11}$, Instituto de Estudos Empresariais ${ }^{12}$, Instituto Liberdade ${ }^{13}$ e Students for Liberty ${ }^{14}$. Juntamente com Rosa Ling, sua irmã, eles são donos da Évora S.A - Holding Company, uma transnacional brasileira com atividades em oito países e que controla empresas como a Fitesa, Crown, America Tampas e a Rio Novo Florestal ${ }^{15}$. Assim como a família Gerdau ${ }^{16}$, a família Ling 
apresenta-se como uma das grandes financiadoras de think tanks. De acordo como o site da Évora S.A. - Holding Company, ao longo de 21 anos, a família Ling, por meio do Instituto Ling, já investiu mais de US\$ 5,5 milhões na educação por meio de programas de bolsas para financiamento de cursos no exterior.

O Instituto Liberdade (IL-RS) ${ }^{17}$ apresenta-se como outro exemplo significativo dessa conectividade, tendo em vista a robustez de sua cadeia de relações, envolvendo instituições públicas e privadas, canais de mídia nacionais e internacionais, grupos empresariais e uma vasta gama de think tanks. Alguns desses atores são apresentados na Figura 2. 
Figura 2 - Quadro funcional e rede de relações institucionais do IL-RS em 2014

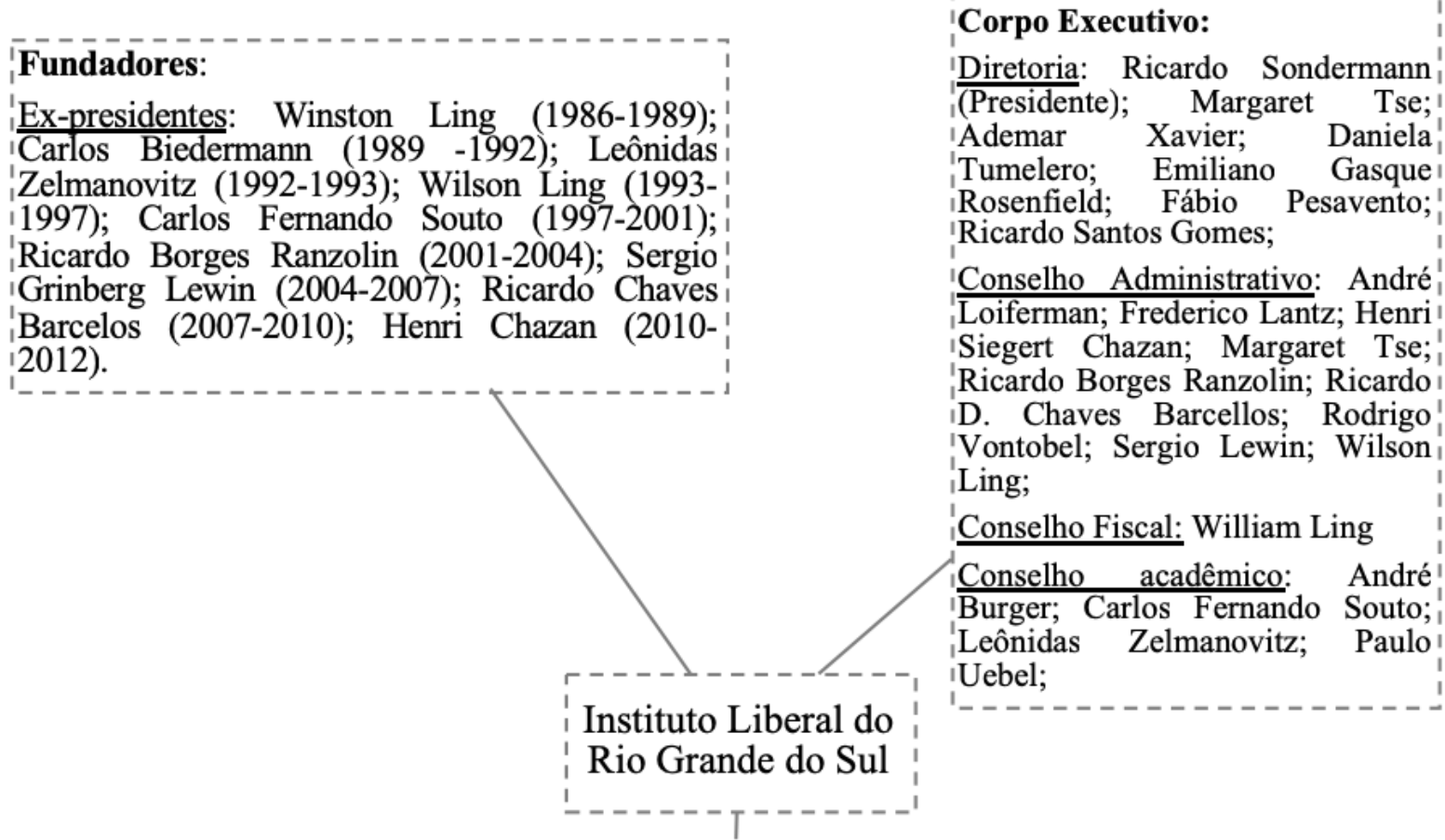

'Parceiros Nacionais: Bom Dia Brasil; Câmara de Dirigentes Lojistas (CDL) de Porto Alegre; Democratas RS; Estado de São Paulo; FEDERASUL; Folha online; Fórum da Liberdade; Fórum । 'Liberdade e Democracia; Instituto Alfa e Beto; Instituto de Estudos Empresariais; Instituto de Estudos' 'Tributários; Instituto de Formação de Líderes - Belo Horizonte; Instituto de Formação de Líderes - Rio । 'de Janeiro; Instituto de Formação de Líderes - São Paulo; Instituto Gerdau; Instituto Liberal do Centro-' 'Oeste - ILCO; Instituto Liberal do Nordeste - ILIN; Instituto Liberal do Rio de Janeiro; Instituto Líderes Ido Amanhã; Instituto Ling; Instituto Ludwig von Mises Brasil; Instituto Millenium; Instituto Vonpar; 'Jornal da Globo; Jornal da Tarde; Jornal do Brasil; Jornal do Comércio; Jornal Nacional; Lojas Renner;, O Globo; OAB/RS; Rádio Globo FM; RBS TV; Revista Época; Revista Exame; Revista Isto É;। 'Revista Veja; Todos pela Educação; Tribunal de Justiça do Estado do RS; TV Bandnews; TV Record'

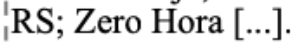

'Parceiros Internacionais: Acton Institute; ALDE - Alliance of Liberals and Democrats for Europe; 'Atlas Economic Research Foundation; Cato Institute; Climate Science Coalition of America;! 'Competitive Enterprise Institute; Economist; Emerging Markets Health Network; European Union-Latin' America and Caribbean Foundation (EU-LAC Foundation); Financial Times; Foundation for Economic 'Education; Foundation for Educational Choice; Fox News; Friedrich Naumann Foundation for Freedom;' |Friedrich Naumann Foundation for Liberty/ Philippines; Fund for American Studies - Latin America; 'Fundación Atlas 1853; Fundacion Bases - Bases Foundation; Fundación Libertad; George Washington' 'University; Grassroot Institute of Hawaii; Hacer; Heartland Institute/Climate Change Conference;' Heritage Foundation; Hoover Institution; Hudson Institute; Human Progress; Ideas for a Free Society; 'IMANI; Center for Policy and Education; Institute for Humane Studies; Institute of Economic Affairs; Instituto Ecuatoriano de Economía Política; Instituto Ludwig von Mises Portugal; International Climate । 'Science Coalition; International Day of Freedom 2012; International Policy Network [...].

Fonte: Elaborado a partir de http://www.il-rs.org.br/site/home.php. 
Como destacamos, chama a atenção a grande teia intersetorial de relações que o IL-RS declara ter, englobando a mídia (Bom Dia Brasil, Estado de São Paulo, Folha online, Revista Época; Revista Exame; Revista ISTOÉ, Financial Times, Fox News etc.), instituições públicas (Tribunal de Justiça do Estado do RS), partidos políticos (Democratas RS, etc.), setores empresariais (Instituto Ling, FEDERASUL, Lojas Renner, etc.) e outras think tanks (Instituto Gerdau, Instituto Liberal do Rio de Janeiro, Instituto Ling, Instituto Ludwig von Mises Brasil, Instituto Millenium, Atlas Economic Research Foundation, Cato Institute, Heritage Foundation, John Templeton Foundation, etc.).

O Instituto Liberdade - RS é uma das think tanks que mais aborda e tenta influenciar as políticas educacionais, participando do Movimento Todos pela Educação e divulgando o discurso do "Movimento Escola sem partido" a partir de discussões sobre "ideologia de gênero" e "doutrinação" por parte da educação pública.

Essas instituições têm ampla relação com setores empresariais que financiam grande parte de suas atividades. Isso, entretanto, não isenta os grupos empresariais de constituírem centros próprios de gestação de ideias. Esse é o caso do Instituto de Estudos Empresariais IEE que consiste em um grupo seleto de formação de lideranças empresariais fundado por William Ling e Roberto Rachewsky em Porto Alegre. Diferente das demais think tanks, o IEE tem um público-alvo distinto; jovens entre 20 e 32 anos, herdeiros e sucessores de empresas, que são preparados para atuarem como novos líderes a partir das ideias de mercado e livre iniciativa.

Além de atuar na formação de lideranças empresariais, o IEE tem um papel estratégico nessa rede, pois desenvolve desde 1988 o Fórum da Liberdade, considerado o maior evento promotor de debates sobre as ideias e a "cultura da liberdade" na América Latina. O evento reúne um número significativo de pessoas e de organizações empresariais, jurídicas, midiáticas, políticas e da sociedade civil do Brasil e de outros países. Entre os palestrantes que por lá passaram, destacam-se ganhadores do Prêmio Nobel, como James Buchanan. Além disso, sua influência política é percebida pela realização de sabatinas de pré-candidatos à presidência da República ${ }^{18}$.

Com objetivos semelhantes, o Students for Liberty - SFL atua no sentido de "educar, desenvolver e capacitar a próxima geração de líderes da liberdade", se apresentando como a maior "organização estudantil pró-liberdade do mundo". A instituição avalia que nos últimos dez anos foram adicionados 140.000 contatos à rede e realizados 959 eventos, com a presença de 54.314 alunos e ex-alunos nos eventos. Por essa razão, a SFL desempenha um papel estratégico na Atlas network, recrutando e formando "líderes da liberdade" em quase todos os países. Tais líderes, por sua vez, capilarizam a rede em suas regiões. É o caso de Nycollas Liberato (que atua também como diretor de fomento na Atlantos), e Julia Sondermann (filha de Ricardo Sondermann, empresário, membro do conselho consultivo da Atlantos, presidente do IL-RS e associado do IEE).

$\mathrm{O}$ enraizamento das relações da SFL, entretanto, não se dá apenas por essa via. $\mathrm{O}$ Students For Liberty financia polos regionais e nacionais nos diferentes continentes. No nosso caso, há uma SFL-América Latina e um SFL-Brasil. De acordo com a Students For Liberty - Brasil (SFLB), a instituição conta com 1.037 lideranças. 
Desse modo, essa think tank se ramifica a partir da criação e replicação de seu modelo por outras instituições. Esse é o caso da "Estudantes pela Liberdade - EPL", criada por Anthony Ling (filho de Wilson Ling), Fábio Ostermann e Juliano Torres. Esses dois últimos, junto com Felipe Franca, são fundadores do Movimento Brasil Livre - MBL, organizado em meio aos protestos de julho de 2013. Em entrevista à Carta Capital ${ }^{19}$, Juliano Torres detalha a conformação do MBL:

Quando teve os protestos em 2013 pelo Passe Livre, vários membros do Estudantes pela Liberdade queriam participar, só que, como a gente recebe recursos de organizações como a Atlas e a Students for Liberty, por uma questão de imposto de renda lá, eles não podem desenvolver atividades políticas. Então a gente falou: 'Os membros do EPL podem participar como pessoas físicas, mas não como organização para evitar problemas. Aí a gente resolveu criar uma marca, não era uma organização, era só uma marca para a gente se vender nas manifestações como Movimento Brasil Livre. [...]

A mobilização política realizada pelo MBL nas manifestações pelo impeachment de Dilma Rousseff foi relatada na página da Atlas Liberty, a qual destacou Kim Kataguiri como "um astro libertário" ligado à Atlas.

Seguindo a trajetória do mapeamento das relações dos sujeitos coletivos, mostrada na Figura 1, encontram-se dois amplos agrupamentos institucionais que se mobilizam politicamente para intervenção em políticas educacionais. O "Todos pela educação (TPE)" e o "Movimento pela Base" ocupam posição estratégica nas tessituras da rede Atlas Network no Brasil, por concentrarem um grande número de instituições e permitirem a circulação e a concentração de ideias e publicações que articulam e mobilizam proposições do Mercado nas políticas educacionais brasileiras.

O TPE foi lançado em 2006 e reuniu diversos intelectuais e organizações empresariais, entre os quais destacam-se algumas personalidades e instituições de relevância política, econômica e educacional. 
Figura 3 - Quadro funcional e rede de relações institucionais do "Todos pela Educação".

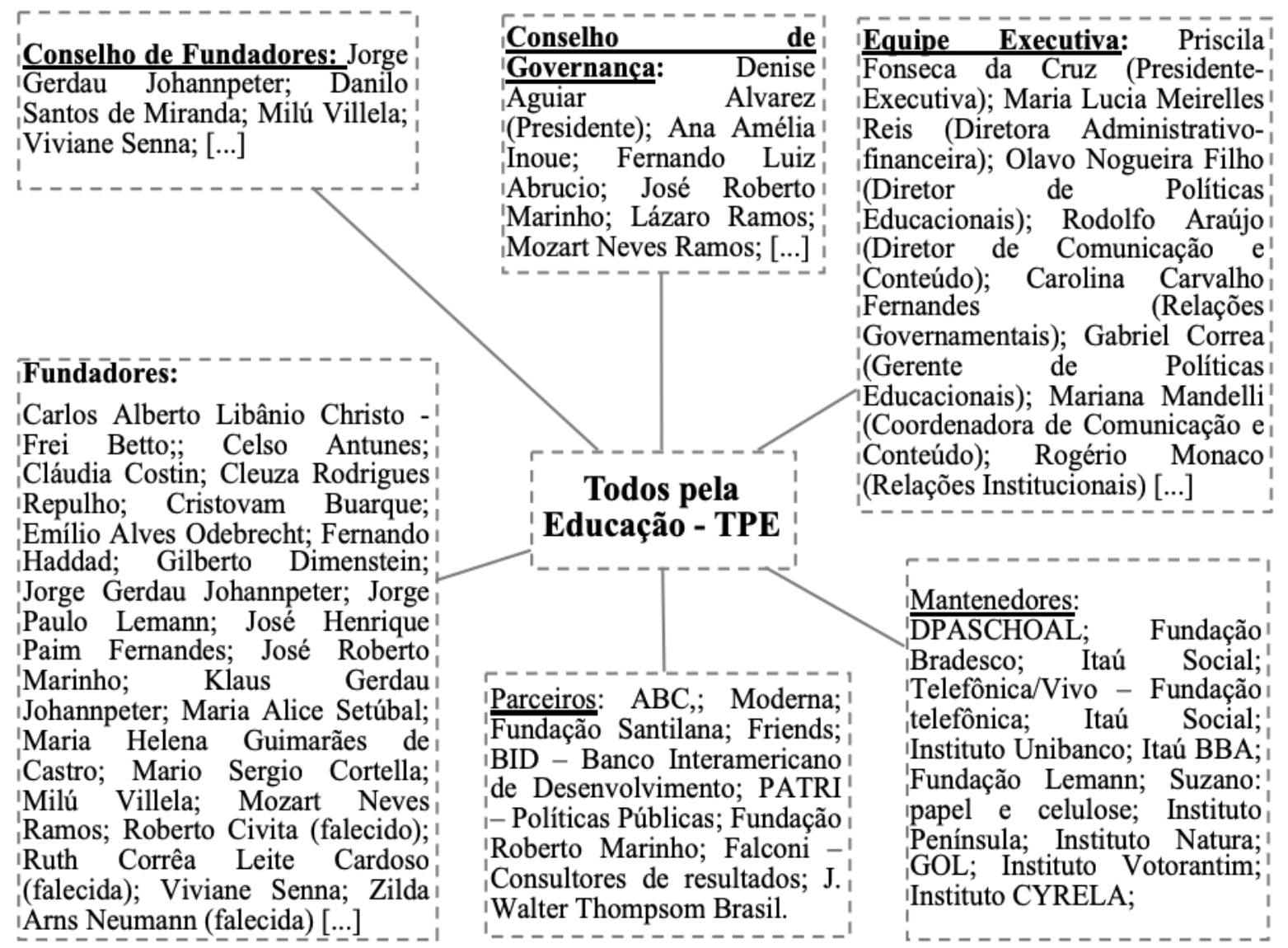

Fonte: Elaborado a partir de https://www.todospelaeducacao.org.br.

Entre as relações institucionais do TPE, destacam-se a presença de representantes ou ocupantes de cargo de destaque no setor público. Esse é o caso de Fernando Haddad (esteve à frente do Ministério da Educação e da Prefeitura de São Paulo), de Cláudia Costin (foi secretária de Educação do Rio de Janeiro) e Maria Helena Guimarães de Castro (esteve à frente do Inep e da Secretaria Executiva do MEC).

A presença de tais agentes do setor público é um exemplo das novas formas de relação entre público e privado, constituídas por redes com ligações horizontais e verticais entre diferentes instituições e setores, proporcionando assim as condições que fazem circular os discursos, interesses e objetivos do Mercado (AVELAR; BALL, 2017). Por meio desse processo, tais agentes promovem o fluxo de ideias e interesses econômicos que vai sendo absorvido pelo setor público, dissolvendo assim os limites entre Estado e Mercado. 
O TPE foi criado com a missão de reorientar os fins e bases das políticas educacionais, cuja finalidade passaria a ser a capacitação de recursos humanos para o trabalho, bem como a formação de valores e comportamentos sociais alinhados à sociedade competitiva.

O grupo desenvolve estudos, relatórios e balanços sobre políticas públicas como o PNE e a BNCC. A partir desse trabalho são criadas recomendações ao sistema educacional, tal como exposto no documento "Compromisso Todos pela Educação", que foi referenciado no título do Decreto n ${ }^{\circ}$ 6.094, de 24 de abril de 2007: "Plano de Metas Compromisso Todos pela Educação".

Ações de influência do TPE nas políticas educacionais também se encontram na formulação do PNE 2014-2024, que contou com a presença de Mozart Neves Ramos e Priscila Cruz (representando oficialmente a TPE) no processo de produção do documento.

Além deles, destaca-se a presença de associados do TPE, mas representando outras instituições, como é o caso de Cleuza Rodrigues Repulho (União Nacional dos Dirigentes Municipais de Educação - Undime), Thiago Peixoto (Conselho Nacional de Secretários de Educação - Consed), Cláudia Costin (Secretária de Educação do Rio de Janeiro), Claudio de Moura Castro (Grupo Positivo), Maria Helena Guimarães de Castro (Professora da Unicamp e membro do Conselho Estadual de Educação - SP), José Henrique Paim Fernandes (Secretário executivo do MEC), Guiomar Namo de Mello (Educadora), entre outros.

É de se notar que, em função das posições políticas e institucionais que tais indivíduos ocupam, há uma chance significativa de que ocorra o fluxo de ideias entre elas (AVELAR; BALL, 2017). Nesse sentido, consideramos a convergência de discursos em muitas dessas câmaras de discussão, visto que na única audiência pública realizada pela Câmara do Deputados sobre "Qualidade da Educação" (11/05/2011) ${ }^{20}$, Mozart Neves Ramos, Cleuza Rodrigues Repulho e Thiago Peixoto representavam mais de cinquenta por cento dos participantes.

Em associação direta com o TPE, a Fundação Lemann tem sido um notável e exímio ator na promoção e no incentivo à reforma das políticas curriculares brasileiras. Por meio de mecanismos diversificados, esse sujeito coletivo/individual tem atuado de forma a influenciar, produzir, financiar e implementar políticas educacionais. A fundação foi criada pelo empresário Jorge Paulo Lemann, considerado o homem mais rico do Brasil com uma fortuna estimada em U\$ 27,4 bilhões ${ }^{21}$.

A Fundação Lemann e seus parceiros têm desenvolvido programas, projetos e campanhas de educação que influenciam, desenvolvem e implementam políticas educacionais nas escolas, tais como o Programa "Formar"; Programa de Apoio ao Desenvolvimento de Lideranças Públicas e o Lemann Fellowship. Além desses programas, são listados outros projetos e iniciativas como Nova Escola, Gestão Escolar, FGV/EBAPE Centro de Excelência e Inovação em Políticas Educacionais, Instituto Sou da Paz, Parceiros da Educação, Todos pela Educação, Movimento pela Base, entre outros.

As parcerias e o modo de atuação da Fundação Lemann (assessorias, consultorias, pesquisas, avaliações e redes de formação e implementação de políticas) no setor público são mais um exemplo de relações cada vez mais entrelaçadas entre Estado e Mercado. Turvamse e confundem-se seus limites, tornando porosas as fronteiras, hibridizando os espaços, os 
interesses e as responsabilidades na área da educação (AVELLAR; BALL, 2017; BALL, 2014). Tais confluências são verificadas com a presença e a influência da instituição nas discussões e definições da recente reforma do Ensino Médio e na aprovação da BNCC.

A reforma do Ensino Médio contou com a participação de Denis Mizne, diretorexecutivo da Fundação, convidado a integrar as audiências públicas da Comissão Mista da Medida Provisória ${ }^{\circ} 746$ de 2016. Nessas discussões, a Fundação Lemann contou ainda com o apoio de representantes de outras instituições parceiras, como o Instituto Unibanco, a Fundação Itaú, o Instituto Inspirare, o Todos pela Educação, o Instituto Natura e o Instituto de Corresponsabilidade pela Educação (ICE).

Já no processo de desenvolvimento e definição da Base Nacional Comum Curricular (BNCC), muitas vezes a Fundação foi o único grupo empresarial a participar. Um exemplo foi a reunião ocorrida no Ceará, em que foi discutida a implantação da BNCC a partir do sistema de bonificação de escolas implementado no estado.

Contudo, a participação da Fundação Lemann na definição e aprovação da Base Nacional Comum Curricular não esteve restrita a esses encontros, pois desde 2013 a Fundação organizou e vem financiando o projeto "Movimento pela Base Nacional Comum MBNC", que mobiliza atores coletivos e individuais públicos e privados em torno da aprovação da BNCC.

O principal objetivo do MBNC é facilitar o desenvolvimento de uma base nacional comum de qualidade para os currículos, entendendo tal base como a concretização dos "direitos de aprendizagem" dos alunos e como um elemento central para o desenvolvimento da educação de qualidade e igualitária. No quadro funcional e das redes institucionais do movimento, destacam-se de atores individuais e coletivos com grande representação acadêmica e política no país. 
Figura 4 - Sujeitos coletivos e individuais do Movimento pela Base Nacional Comum

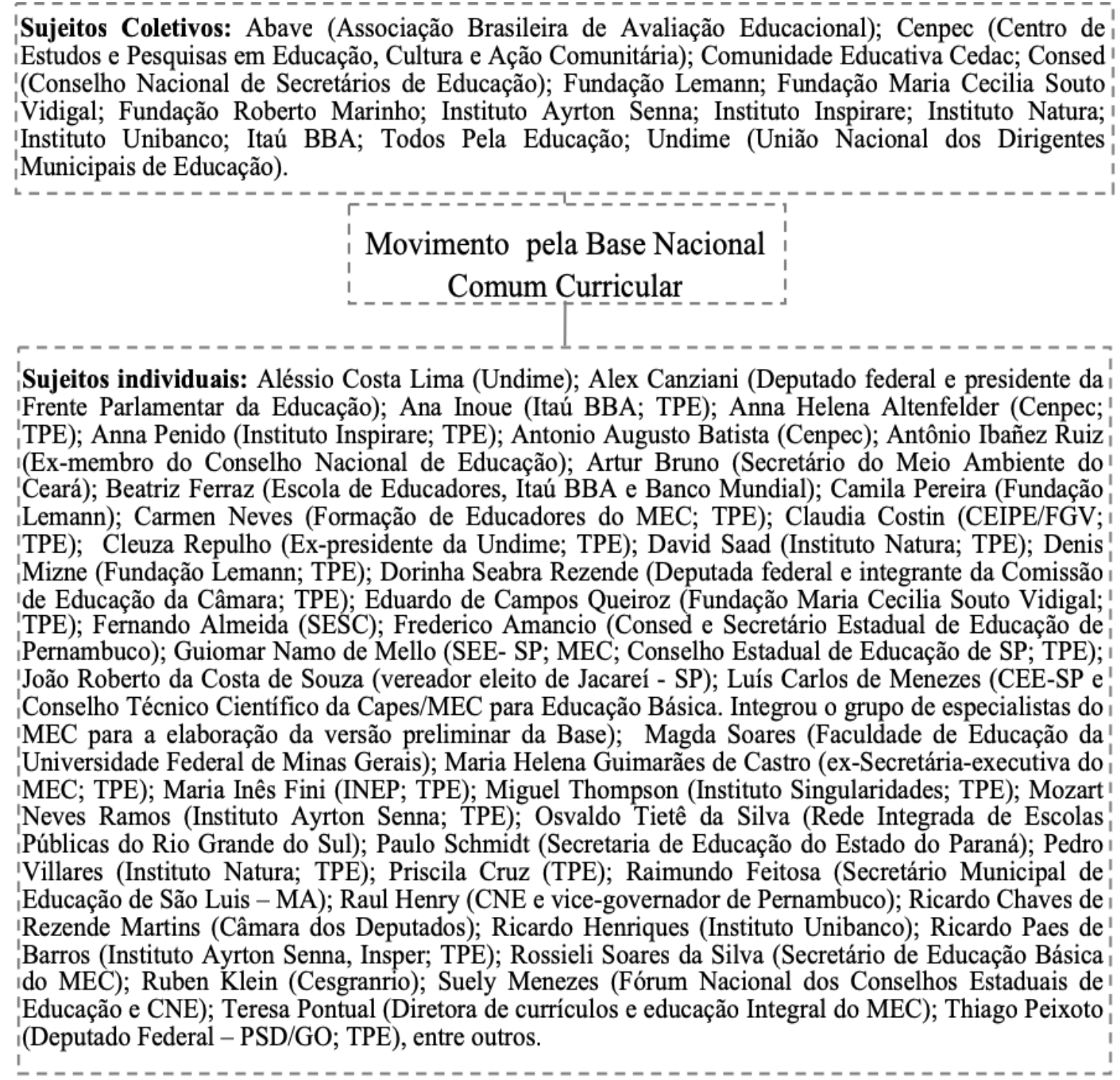

Fonte: Elaborado a partir de http://movimentopelabase.org.br.

$\mathrm{Na}$ composição do MBNC, nota-se que quase 50\% dos associados e instituições de fomento são cofiliados ao TPE, o que representa um estreitamento e uma extensão das ideias e dos objetivos entre essas think tanks. Além disso, percebe-se grande número de agentes públicos, dando-lhe uma constituição mista com sujeitos individuais e coletivos de setores empresariais, públicos e de entidades filantrópicas. No caso dos setores públicos, atuam instituições representativas como o CONSED, a UNDIME e indivíduos ocupantes de cargos públicos em secretarias de educação, diretorias e chefias diversas do Ministério da Educação. 
Os dados de Avellar e Ball (2017) sobre a morfologia da composição do MBNC são importantes aqui, pois mostram um aumento do número de servidores públicos nos quadros do movimento.

Figura 5 - Composição da MBNC entre 2015 e 2016

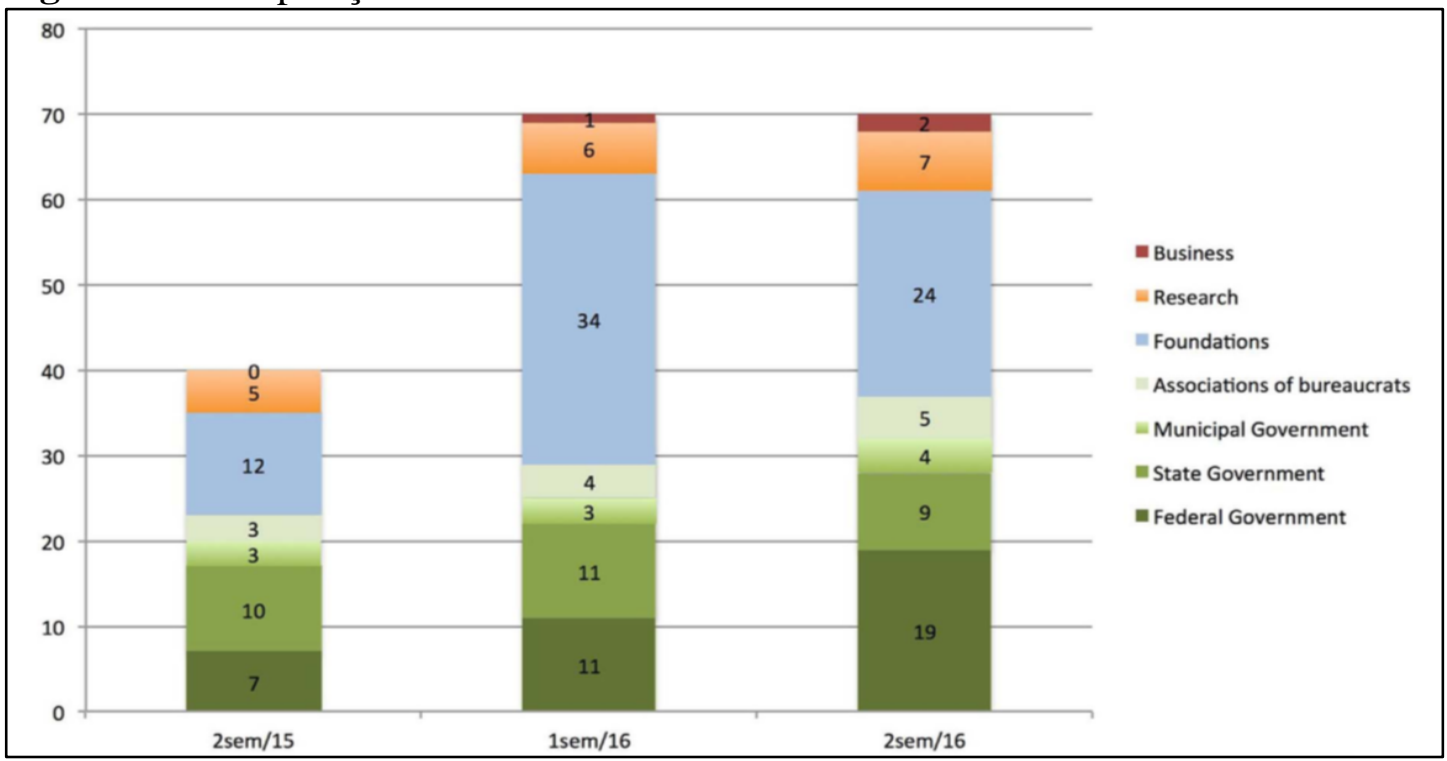

Fonte: (reproduzido de AVELAR; BALL, 2017)

Os dados dos autores apresentam mudanças quantitativas e qualitativas sobre a composição dos atores no MBNC, que passam de 40 para 70 sujeitos coletivos e individuais, com um aumento expressivo e contínuo de servidores federais (estes saltando de 7 para 19). Esse aumento, todavia, não expressa a entrada de novos atores ao movimento, mas sim a posse de filiados da Fundação Lemann e do Todos pela Educação em cargos públicos diversos. Esse é o caso de Maria Helena Guimarães de Castro (que assumiu a secretaria executiva do MEC), de Maria Ines Fini (que assumiu a presidência do Instituto Nacional de Estudos e Pesquisas Educacionais Anísio Teixeira - Inep) e de Teresa Pontual (que assumiu a Diretoria de Currículos e Educação Integral do MEC).

Essa forma com que o MBNC se compõe e se organiza dá mobilidade aos discursos e interesses do grupo, que penetram com mais facilidade nos espaços políticos, produzindo assim sentido e resultados às ações de formação de líderes promovidas e financiadas pela Fundação Lemann. Em 2016, durante o 25 aniversário da Fundação Estudar, o próprio Jorge Lemann reforça essa ideia:

[...] eu espero é que algum dos bolsistas da fundação venha a ser presidente do Brasil, e aí arraste um bando de outros bolsistas, porque uma das coisas que nós damos muita ênfase é todo um network entre todos esses bolsistas, para eles se 
conhecerem, ajudarem uns aos outros e, se alguém for para um cargo elevado e levar vários outros com ele, nós vamos ter um Brasil muito melhor [...]

(LEMANN, 2016. Disponível em: < https://www.youtube.com/watch?v=RxHk7T6nMI0>).

Tal estratégia cria novos tipos de atores políticos, com caráter híbrido e de grande interesse para a rede, pois circulam entre os setores público e privado, exercendo papéis e identidades duplos no interior das arenas de produção política.

Compreende-se, portanto, que tais redes - tendo as think tanks como unidades principais de ação - têm ocasionado prejuízo aos processos de participação na construção de políticas públicas, uma vez que as vozes na tomada de decisão pública são dissolvidas em um discurso homogêneo e ações previstas na legislação são (re)direcionadas a atender os interesses particulares do mercado (MIRANDA, 2019). Esse dado indica a necessidade de outras pesquisas sobre o impacto da ação dessas redes nas diretivas proposta por movimentos sociais e progressistas na sociedade.

\section{Discursos, mecanismos, artefatos e formas de influência em políticas}

A constituição e associação da rede Atlas Liberty Network se dá, em grande parte, pelo compartilhamento de objetivos, discursos e ideias políticas ligadas ao Neoliberalismo. Em todas as think tanks mapeadas percebe-se o discurso de defesa do Estado de Direito, da democracia representativa, da economia de mercado, da descentralização do poder, da livre iniciativa, da propriedade privada, do lucro, da meritocracia, da competitividade, da responsabilidade individual e da igualdade jurídica.

Entretanto, para que esses discursos tenham uma circulação efetiva, a ponto de provocar mudanças nos diferentes contextos educacionais públicos, entende-se que é necessário que eles conversem com as diversas realidades e se traduzam em práticas na gestão escolar e na sala de aula. A partir desse entendimento, destacam-se os discursos, mecanismos, artefatos e formas de atuação utilizados pelas think tanks para tradução da proposta neoliberal nas políticas educacionais e no espaço escolar.

\section{Discursos neoliberais e influências nas políticas educacionais}

De forma geral, identificamos o uso do discurso da má qualidade da educação como mote, justificativa e respaldo para implantação de uma cultura de performatividade e meritocracia e da privatização/terceirização da educação por meio do sistema de vouchers.

Esse discurso serviu de base para construção das propostas de ação do Todos pela Educação e foi utilizado como argumentação do Movimento pela Base. Na definição de sua missão, o Todos pela Educação assume o compromisso de "contribuir para que [...] o País (sic) assegure educação Básica pública de qualidade a todas as crianças e jovens” 
(https://www.todospelaeducacao.org.br/quem-somos/o-todos/). O MBNC argumenta que "Como política pública, a BNCC tem o potencial de desencadear uma série de mudanças em direção a uma educação mais igualitária e de alta qualidade” (LEMANN, 2016).

Contudo, pode-se afirmar que a preocupação dessas think tanks com a qualidade da educação está comprometida, sobretudo, com a melhoria da "capacidade competitiva do país" (MARTINS, 2009; 2016). Essa noção de qualidade da educação tem funcionado como um mecanismo articulador das ideias de reforma educacional patrocinadas por essas instituições (MACEDO, 2009). Uma delas é a construção de um sistema de avaliação, controle e desempenho dos alunos em exames de larga escala. Tal sistema funciona como base para o desenvolvimento de uma cultura de performatividade e meritocracia.

$\mathrm{O}$ discurso das competências, articulado pelas think tanks aqui apresentadas, assume o sentido relacionado com a qualificação para o mundo do trabalho e a constituição de uma gestão de recursos humanos para o mercado. Esse sentido foi defendido por Eugênio Mussak (escritor e fundador da Sapiens Sapiens; consultor em Desenvolvimento Humano e Organizacional — DHO; professor do IBMEC-São Paulo; professor convidado da FIA; professor da Fundação Dom Cabral e membro da Associação Brasileira de Recursos Humanos - ABRH ) no painel Educação do $27^{\circ}$ Fórum da Liberdade (2014), que reuniu nomes como Chris Arnold (presidente da The Smaller Earth Group) e Rodrigo Constantino.

De forma geral, os discursos nesse painel estiveram centrados na defesa de uma educação voltada para formação de jovens empreendedores, em que fossem potencializadas competências e habilidades orientadas para o mercado de trabalho enquanto plano de vida dos sujeitos. Eugênio Mussak defendeu que é necessário que a educação assuma a ideia de competência como objetivo principal, pois passaria a ter um mecanismo gerencial mais objetivo a partir do qual poderia administrar com eficiência seus resultados e recursos. De acordo com Mussak, as competências funcionariam como critérios de aferição da eficiência e "produtividade" do sistema educacional.

Outra proposta consiste no discurso das expectativas/direitos de aprendizagem. O debate a respeito dessas categorias surgiu durante a elaboração do PNE. No caso, foi sugerida a substituição do termo "expectativas" por "direitos de aprendizagem" a fim de evitar uma ideia pragmática de educação baseada na regulação e competitividade e garantir que a proposta do PNE fosse significada dentro de uma perspectiva de educação enquanto direito público subjetivo (MACEDO, 2015).

Contudo, a perspectiva curricular que orienta esses parâmetros também os constrange e os tensiona, voltando-os para um sentido de metas a serem mensuradas, sob a alegação da necessidade de verificação da efetividade do direito. Essa ideia é expressa na descrição e justificativa apresentada pelo TPE para os direitos de aprendizagem:

Embora o País conte com a chamada Prova Brasil, com o Índice Brasileiro da Educação Básica (Ideb) e com metas para as redes e as escolas, ainda não foram definidos os direitos de aprendizagem, as expectativas dos alunos brasileiros por série ou por ciclo. Ou seja, os exames acabam cobrando algo que nunca foi estabelecido pelo estado nem alinhado previamente com as escolas. 
Faz-se urgente, portanto, elaborar e adotar esses direitos, para que as redes, as escolas e os professores saibam a que objetivos pedagógicos precisam responder. (https://www.todospelaeducacao.org.br, grifos nossos).

No caso, o sentido de "direitos de aprendizagem" é explicado como algo que é cobrado, que será exigido, que deverá ser cumprido em determinada situação; o que, no contexto do excerto, ocorre nas avaliações de larga escala. Dessa forma, se produz uma conotação de um sentido pragmático de meta a ser alcançada, reforçando a ideia de gerenciamento e regulação do sistema educacional. Deslocando e esvaziando assim o sentido de direito subjetivo.

Corrobora com essa percepção o fato da Base Nacional Comum Curricular, na introdução do documento geral, representar os direitos de aprendizagem de forma conjugada aos objetivos, competências e habilidades, ao destacar que:

Trata-se, portanto, de maneiras diferentes e intercambiáveis para designar algo comum, ou seja, aquilo que os estudantes devem aprender na Educação Básica, o que inclui tanto os saberes quanto a capacidade de mobilizá-los e aplicá-los (BRASIL, 2017, p. 12).

Isso reforça nossa consideração de que as intenções da proposição dos direitos de aprendizagem acabam sendo envolvidas em uma lógica de performatividade, mesmo que sua proposta seja contrária a esta. Isso ocorre em razão de seus significados serem deslocados, pois o sentido de "direito" enquanto um amplo e complexo sistema de "ordenamento normativo" - que envolve garantias, moralidade, disposições positivas e negativas entre Estado e sociedade (BOBBIO, 1993) - é reduzido a um sentido de critério de avaliação.

Analisando em perspectiva, percebe-se que os discursos veiculados pelas think tanks, com destaque para a atuação do TPE e do MBNC, tentam articular a construção de uma cultura de performatividade/meritocracia por meio de um sistema de performance em exames de larga escala.

Essa proposta foi abordada no $28^{\circ}$ Fórum da Liberdade, no painel "Educação e Meritocracia", do qual participaram Fernando Schüler (professor no Insper e Curador do Projeto Fronteiras do Pensamento) e Rodrigo Galindo (CEO da Kroton Educacional). Nas discussões apresentadas no painel, foi defendida a ideia de um modelo de educação baseada em uma cultura de meritocracia com extensão na gestão educacional pública e em sala de aula. A performatividade seria o mecanismo de operacionalização dessa ideia, no sentido em que seriam destinados incentivos e recursos a sujeitos e escolas conforme o desempenho em avaliações de larga escala: "Você premia resultados educacionais em todos os níveis: resultados educacionais, resultados da conceituação de metas, avaliação qualitativa, nota, ENADE, ENEM etc., de acordo com o nível etc.” (SCHÜLER, 2015 22).

Por fim, destacamos a proposta de privatização/terceirização da educação a partir da implantação de vouchers. Essa proposta tem sido difundida e defendida por vários atores individuais e coletivos da rede, a exemplo do deputado Tiago Mitraud (foi presidente da Brasil Júnior e diretor executivo da Fundação Estudar, ligadas à Fundação Lemann) que 
propôs, junto com o deputado Marcelo Calero, a emenda $n^{\circ} 3$ à Proposta de Emenda à Constituição $n^{\circ}$ 15/2015 (busca tornar o FUNDEB instrumento permanente de financiamento da Educação Básica pública), propondo:

- alterar o $§ 10$ do art. 213 da Constituição Federal, que trata dos recursos públicos, de modo a serem distribuídas bolsas de estudo para o ensino básico, na forma da lei, para os interessados inscritos e selecionados que demonstrarem insuficiência de recursos, quando houver instituições cadastradas segundo requisitos definidos em lei na localidade da residência do educando.

No âmbito da rede, essa discussão foi pautada no $27^{\circ}$ Fórum da Liberdade, no painel Educação, em que Rodrigo Constantino destacou que "os educadores claramente falharam, fracassaram em entregar um produto decente no Brasil". A solução oferecida por ele consiste em retirar a educação das "mãos do Estado" e entregá-la ao mercado que, por meio de uma cultura meritocrática, conseguiria regular, estimular e elevar a educação a padrões de eficiência reconhecidos pelo mercado. Um dos modos apresentados para operacionalizar essa proposta seria dar poder de escolha às famílias por meio da concessão estatal de vouchers, que lhes possibilitaria escolher o tipo de educação mais adequada conforme seus princípios e crenças. Segundo Sérgio Lewin (2011) ${ }^{23}$ :

O sistema do 'vale-educação' é um modo de operar a democracia na prática, permitindo aos alunos com menores condições financeiras a escolha do estabelecimento de ensino em que estudarão, tirando esta decisão do governo [...] A adoção deste modelo na educação deve ser apenas o prenúncio da contratação que o Estado deve fazer da iniciativa privada também em outros setores.

Esse seria o sentido real do sistema de vouchers, qual seja; um mecanismo de financiamento do mercado pelo Estado, uma vez que a atuação do Estado é reduzida e a regulação da área é deixada ao mercado, que operará por meio da relação de mão invisível (BALL, 2014). Ball (2014) relata que a implantação do sistema de vouchers na Índia, articulada por uma vasta gama de think tanks (incluindo a Atlas, o Instituto Cato e o protagonismo de James Tooley), veio acompanhada de todo um complexo sistema de microfinanciamento, proporcionando a explosão de escolas privadas e constituindo a educação como um novo nicho de mercado.

\section{Mecanismos, artefatos e formas de influência das think tanks}

A atuação das think tanks é caracterizada sobretudo pela produção, publicação e divulgação de pesquisas e estudos, com os quais se pretende influenciar as políticas públicas. Nesse sentido, Teixeira (2007) considera esses grupos como "reservatórios de ideias", geralmente, liberais e neoconservadoras, que são disseminadas tentando influenciar a produção de políticas públicas e a tomada de decisão política. 
A utilização de pesquisas e estudos enquanto mecanismo de atuação das think tanks busca conferir legitimidade ao seu discurso, utilizando-os como mecanismo de comprovação dos problemas identificados e de suas propostas de resolução. Dessa forma, tenta atribuir um status de verdade ao seu discurso, provando empiricamente o que é dito. No caso, destacamse produções com levantamentos de dados, processos de análise e recomendações para a área educacional.

Nessa linha, destacamos as pesquisas do Todos pela Educação e do Movimento pela Base. A exemplo, a análise realizada pelo TPE, em "Apenas 9,3\% dos alunos do Ensino Médio aprenderam o adequado em matemática em 2013", de 23 de dezembro de $2014^{24}$, discute a "proficiência dos alunos nas avaliações da Prova Brasil e do Saeb" de 2013, sendo apontados resultados "considerado[s] adequado[s] pelo movimento" em Matemática, e [...] em Português, mas ficando abaixo da "meta intermediária* definida pelo TPE para o ano de 2013" [...] (grifo nosso).

Esse tipo de análise e estudos atua na construção e reafirmação dos problemas educacionais formulados pela rede, que consistem principalmente na má qualidade da educação. Esses problemas, no entanto, são formulados e seguem critérios próprios de avaliação que, no exemplo apresentado, baseiam-se nos parâmetros dos exames de larga escala e nos critérios do TPE. A partir das questões levantadas pelas think tanks, são realizadas recomendações para que as propostas educacionais, sobretudo as curriculares, enquadrem-se nos padrões por elas estabelecidos.

Os estudos e pesquisas são, também, comprados ou tomados de empréstimo. O MBNC, por exemplo, encomendou diversas avaliações das versões preliminares da BNCC, realizadas principalmente pela Curriculum Foundation, pela Australian Curriculum Assessment and Reporting Authority - ACARA e por coautores do Common Core dos EUA. No caso, são listados estudos como: "Dimensões e Desenvolvimento das Competências Gerais da BNCC" (s/d); Análise dos textos introdutórios da BNCC pela ACARA (20/06/2016); Análise dos textos introdutórios pela Curriculum Foundation (05/2016); Ciências da Natureza: análise do Curriculum Foundation (05/2016), entre outros ${ }^{25}$.

Outra forma de atuação, comum às think tanks da rede Atlas, é a realização de eventos, seminários, debates e palestras. Essas práticas funcionam estrategicamente para circulação das ideias e discursos da rede, visando, especificamente, os espaços e arenas de produção da política curricular. Como destacamos, um dos grandes eventos de celebração das ideias neoliberais é o Fórum da Liberdade, organizado anualmente pelo Instituto de Estudos Empresariais.

A maior parte das think tanks apresentadas realiza eventos próprios. O Movimento pela Base, por exemplo, realizou diversos eventos que reuniram dirigentes públicos e pesquisadores pró-base, tais como Susan Pimentel (autora do Common Core State Standards na área English Language Arts/Literacy), Maximiliano Moder (Coordenador de desenvolvimento de conteúdos da Educarchile), Dave Peck (Presidente da Curriculum Foundation), Melanie Isaacs (Gerente de Projeto - Currículo da ACARA), Philip Daro (autor do Common Core de Matemática), entre outros. 
Essas reuniões e eventos têm papel estratégico para ativar a rede e para reafirmar as ideias que a mobiliza (AVELAR; BALL, 2017). Com efeito, alguns desses palestrantes são motivadores e interlocutores (AVELAR; BALL, 2017) que conectam, dão mobilidade e reforçam as propostas políticas que compõem sua cadeia discursiva.

A presença de servidores públicos nesses eventos, sobretudo de dirigentes, como os membros da UNDIME e do CONSED, potencializa também essa lógica. Afinal, nesses espaços diversas formas de agir são sugeridas aos gestores educacionais. Dessa maneira, essas reuniões constituem-se como um modo de atuação política, pois instituições são mobilizadas por meio delas, bem como atores são socializados e relacionamentos são construídos. De acordo com Avelar e Ball (2017, p. 4), "esses eventos são momentos em redes que apoiam a criação, evolução e manutenção de uma rede de políticas dinâmicas, instáveis e em expansão, onde a nova filantropia, os "tecnocratas" de políticas e o Estado podem interagir" (tradução nossa ${ }^{26}$; aspas dos autores).

Essas estratégias de ação caracterizam a rede e essas instituições como uma "comunidade discursiva" que busca a reforma educacional. Nesse sentido, desenvolvem um processo itinerante de empreendimento de políticas, atuando na promoção, divulgação, articulação e tentativa de recontextualização da política na prática. Para realização desse último processo, são utilizados outros artefatos textuais como artigos de jornais, podcasts e matérias em revistas. Entre esses gêneros, destaca-se a estratégia da Fundação Lemann de utilizar a "Revista Nova Escola" como um programa e mecanismo de divulgação e articulação de propostas de interpretação e tradução da Base Nacional Comum Curricular na prática escolar.

A revista Nova Escola contava até o primeiro semestre de 2018 com cerca de 1.217.259 seguidores em sua página no Facebook. Segundo a Fundação Lemann, em 2016, essa mesma página contabilizou cerca de 555 mil usuários diários, mais de 4 milhões de publicações, 220 mil comentários e 893 mil compartilhamentos. Esse potencial de circulação e interação tem sido utilizado para promover a concretização da base em sua versão de lei e na prática de sala de aula. O número 309 — "Base Nacional: as mudanças começam agora" — de fevereiro de 2018 trouxe uma edição completa sobre a BNCC, com artigos que buscam esclarecer questões sobre as formas de atuação escolar nas diferentes disciplinas a partir da base, como mostram as manchetes dos artigos que a compõem: "Da expectativa à realidade [...] Conheça os riscos, os desafios e as oportunidades da sua implementação"; "Educação Infantil - Ler e escrever do próprio jeito [...] compreenda o que cabe à creche e à préescola quando o assunto é alfabetização".

Além disso, são sugeridas formas de atuação e de esclarecimentos aos professores: "História - Não fique amarrado pela cronologia - A organização da BNCC pela ordem dos acontecimentos históricos não impede que você trabalhe por eixos temáticos"; Inglês - O inglês que eles já falam - $\underline{O}$ mundo dos youtubers pode servir de base para o ensino do idioma".

Por fim, ressalta-se outra estratégia de influência da política na prática escolar, qual seja; o oferecimento gratuito de planos de aula. A revista possui uma seção destinada ao 
compartilhamento desses planos em todas as áreas disciplinares, contemplando todos os anos de escolarização e seus respectivos conteúdos curriculares.

Ao serem elaborados por outros professores, a produção de planos de aula usa uma estratégia de aproximação com a comunidade docente. Em parceria com o Google e a Fundação Lemann, a Nova Escola concebeu o programa "Time de autores", que seleciona professores para a produção desses planos. Segundo informações do site ${ }^{27}$, a proposta era que, até o final de 2018, fossem produzidos 6.000 planos de aula a partir das orientações da BNCC.

\section{Considerações Finais}

O propósito deste trabalho foi destacar a atuação de redes de política que têm buscado influenciar as políticas educacionais brasileiras, de modo a introduzir uma forma de pensar, organizar e gerenciar a educação baseada na perspectiva político-econômica do neoliberalismo. Com base nas análises da organização e atuação de uma dessas redes, a Atlas Liberty, destaca-se o protagonismo e a influência, na política educacional, de think tanks como o "Todos pela Educação" e o "Movimento pela Base", que atuam na promoção do discurso neoliberal nos setores públicos. Essa asserção toma como fundamento a análise da organização e composição dessas redes, que apresentam uma extensa capilaridade propiciada por atores políticos com atividades em diferentes instituições e associações, de mídia e da administração pública. Dessa forma, constituem-se conexões pessoais e profissionais, com links horizontais e verticais entre setores, fazendo circular os discursos, interesses e objetivos do mercado na educação (AVELAR; BALL, 2017). Além disso, a presença de atores híbridos, que exercem papéis representativos duplos dentro das arenas de produção de políticas, movendo-se entre tais setores, torna porosas as fronteiras entre público e privado. Novamente, confere-se mobilidade ao discurso da reforma neoliberal na educação brasileira.

Essa nova forma de relação entre Estado e mercado, em que suas linhas divisórias são dissolvidas a partir da atuação de atores políticos híbridos, tem representado prejuízo às arenas de decisão pública, sobretudo nos processos de construção de políticas educacionais, uma vez que os interesses são homogeneizados em torno das demandas do mercado e o processo de tomada de decisão é esvaziado pela falta de participação ampla e de transparência (PERONI; CAETANO; LIMA, 2017; MIRANDA, 2019).

Quanto ao discurso da reforma da educação, este é respaldado pelo trabalho das think tanks da área educacional, que tentam confirmar o fracasso do Estado em prover uma educação pública e comprovar a eficiência das soluções apresentadas pelo mercado. Isso é feito por meio da produção, publicação e divulgação de artigos, estudos, relatórios e balanços das políticas e programas públicos de educação. Nesse sentido, o discurso da má qualidade da educação é apropriado por essas instituições como mote, justificativa e respaldo para a reforma do modelo educacional brasileiro.

Como solução para os problemas da educação, é sugerida a ressignificação das práticas educacionais, voltando-se para o individualismo e a mudança organizacional, adotando o 
modelo gerencialista de mercado. De acordo com os dados, a conformação dessa proposta passaria pela construção de uma cultura de performatividade/meritocracia na educação. Dessa forma busca-se construir uma base de avaliação da eficiência da educação pública a partir da performance dos alunos em exames de larga escala. Para isso, os sentidos de competências/expectativas/direitos de aprendizagem são constrangidos e assumidos como parte dos mecanismos de gerenciamento e controle, à medida que passam a ser entendidos como critérios de eficiência e produtividade da educação. Concebidas nessa lógica, essas propostas de avaliação são esvaziadas de seu propósito político e educacional de acompanhamento/planejamento do desenvolvimento dos sujeitos, admitindo como horizonte o mercado de trabalho. Dessa forma, elementos de formação política dos indivíduos são silenciados e ausentados enquanto componentes de políticas curriculares, como a BNCC.

Esse mapeamento, entretanto, não capta toda a complexidade da rede, uma vez que as relações estabelecidas são fluídas, provisórias e opacas. Não permitem, portanto, acessar e nem mensurar a intensidade das trocas sociais (in)formais, das negociações e compromissos não publicizados. O presente mapeamento é apenas um corte dentro da gama de atividades e relações das quais tais organizações participam, sendo necessária uma análise mais específica dos nós e laços que tecem essas teias de relações que constituem a rede, sobretudo quanto aos aspectos de financiamento e de ação discursiva nas políticas educacionais.

\section{Notas}

1- Corrente do pensamento liberal mais extremada e conservadora.

2- Kroton fecha a compra da Somos Educação por R \$ 4,57 bilhões. <https://www.valor.com.br/empresas/5474105/krotonfecha-compra-da-somos-educacao-por-r-457-bilhoes>.

3- Kroton fecha compra da Somos Educação por R\$ 4,6 bilhões.https://g1.globo.com/economia/noticia/kroton-fechacompra-da-somos- educacao-por-r-46-bilhoes.ghtml>.

4- [...] public policies are today the result of a 'combination of political forces, social sctructures, cultural traditions and economic processes entangled in a matrix of intersecting multi-level,multi-scalar [...]

5- In general terms, network ethnography addresses 'the people, places, and moments' (Prince 2010) involved in the making and remaking of mobile policies and attempts to identify the paths and pipelines, and nodes and activities through which policy moves [...].

6- https://onodo.org

7- Organização internacional criada em 1947 por pensadores como Friedrich von Hayek, Ludwig von Mises, Milton Friedman e Karl Popper em defesa das ideias de liberdade, com referência ao Liberalismo Clássico, que posteriormente veio a fundamentar propostas econômicas neoliberais.

8- https://www.atlasnetwork.org/partners/global-directory/latin-america-and-caribbean

9- https://www.institutomillenium.org.br/camara-de-fundadores-curadores/

10- Patrícia Carlos de Andrade é filha do jornalista Evandro Carlos de Andrade (1931-2001), que trabalhou como diretor de redação de "O Globo" (1971 e 1995) e como diretor da Central Globo de Jornalismo (1995 e 2001). Trabalhou nos bancos Icatu e JPMorgan.

11- https://www.institutoliberal.org.br;

12- http://iee.com.br/custom_type/;

13- http://www.il-rs.org.br/site/home.php;

14- https://www.studentsforliberty.org/team/; 
15- https://www.evora.com

16- A família Gerdau desenvolve relações institucionais com grande parte das think tanks aqui mapeadas como Instituto Ling, Instituto Liberdade, Instituto Millenium, Instituto de Estudos Empresariais e Todos pela Educação.

17- Informações baseadas no site: http://institutoliberdade.com.br.

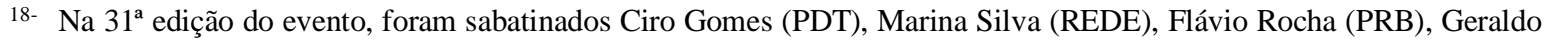
Alckimin (PSDB) e João Amoedo (Partido NOVO).

19- AMARAL, M. A nova roupa da direita. Carta Capital, 06 de julho de 2017. Disponível em: <https://www.cartacapital.com.br/politica/a-nova-roupa-da-direita-4795.html >. Acesso em: 07/07/2017.

20- BRASIL. Plano Nacional de Educação 2014-2024: Lei no 13.005, de 25 de junho de 2014, que aprova o Plano Nacional de Educação (PNE) e dá outras providências. - Brasília: Câmara dos Deputados, Edições Câmara, 2014.

21- Os bilionários mais ricos do mundo em 2018. Revista Época, 06/03/2018. Disponível em: $<$ https://epocanegocios.globo.com/Empreendedorismo/noticia/2018/03/dono-da-amazon-jeff-bezos-lidera-lista-demais-ricos-do-mundo-da-forbes.html >.

22- SCHÜLLER, F. Inovação, Educação e Meritocracia. In: Painel "Educação e Meritocracia", $28^{\circ}$ Fórum da Liberdade, Porto Alegre/RS, 13 e 14 de abril de 2015. Disponível em https://www.youtube.com/watch?v=icRvsY0UsDY.

23- LEWIN, S. Nova Educação. Jornal Zero Hora. 21/03/2011. Disponível em: http://www.ilrs.org.br/site/info/det_escoeduc.php?recordID $=519$.

24- Disponível em: http://www.todospelaeducacao.org.br/reportagens-tpe /32325/apenas-93-dos-alunos-do-ensino-medioaprenderam-o-adequado-em-matematica -em-2013/;

25- Arquivos completos das análises disponíveis em: http://movimentopelabase.org.br/biblioteca/;

26- "These events are sites that support the creation, evolution and maintenance of a dynamic, unstable and expanding policy network, where new philanthropy, policy 'technocrats' and the state can interact."

27- Para mais informações ver: https://fundacaolemann.org.br/noticias/planos-de-aula-matematica-feitos-por-professores.

28- Os objetivos e propostas dos programas podem ser consultados em https://fundacaolemann.org.br/transformamos;

29- Disponível em https://www.youtube.com/watch?v=icRvsYOUsDY;

\section{Referências Bibliográficas}

AVELAR, M.; BALL, S. Mapping new philanthropy and the heterarchical state: The Mobilization for the National Learning Standards in Brazil. International Journal of Educational Development, 2017.

AVELAR, M.; NIKITA, D. P.; BALL, S. Education Policy Networks and Spaces of 'Meetingness: a network ethnography of a Brazilian Seminar. In: VERGER, A.; NOVELLI, M.; ALTINYELKEN, H. K. Global Education Policy and International Development: new agendas, issues and policies. 2. ed. London: Bloomsbury, 2018.

BARABÁSI, A. L. Linked: a nova Ciência dos Networks. São Paulo: Leopardo Editora, 2009.

BALL, S. J. Big Policies/Small World: An introduction to international perspectives in education policy. Comparative Education, v. 34, n. 2, 1998.

Reformar escolas/reformar professores e os terrores da performatividade. Revista Portuguesa de Educação, v. 15, n. 2, 2002.

Performatividade, privatização e o pós-Estado do bem-estar. Educ. Soc., v. 25, n. 89, 2004.

Profissionalismo, Gerencialismo E Performatividade. Cadernos de Pesquisa, v. 35, n. 126, 2005.

Sociologia das políticas educacionais e pesquisas crítico-social: uma revisão pessoal das políticas

educacionais e da pesquisa em política educacional. In: BALL, S.; MAINARDES, J. (Org.). Políticas

Educacionais: questões e dilemas. São Paulo: Cortez, 2011. 
Educação Global S.A.: novas redes políticas e o imaginário neoliberal. 23. ed. Ponta Grossa - Paraná: UEPEG, 2014.

Following policy: networks, network ethnography and education policy mobilities. Journal of Education Policy, v. 31, n. 5, 2016.

BALL, S. J.; MAGUIRE, M; BRAUN, A. How Schools do Policy: Policy Enactments in Secondary Schools. New York: Routledge, 2012.

BALL, S. J.; JUNEMANN, C. Networks, New Governance and Education. Bristol: Policy Press, 2012.

BALL, S. et al. A constituição da subjetividade docente no Brasil: um contexto global. Revista Educação em Questão, Natal, v. 46 n. 32, 2013.

BAUTHENEY, K.C.S.F. Incongruências no discurso sobre Qualidade da Educação Brasileira. Est. Aval. Educ., São Paulo, v. 25, n. 57, p. 138-162, jan./abr, 2014.

BERNARDI, L. M.; BOROWSKY, F.; MONTANO, M.; SUSIN, M. O. Os think tanks liberais no País: a Universidade Aberta de Porto Alegre. Revista Retratos da Escola, Brasília, v. 11, n. 21, 2017.

BOBBIO, N. Direito. IN: BOBBIO, N.; MATTEUCCI, N.; PASQUINO, G. Dicionário de política. 5. ed. Tradução: Carmen C. Varriale et al. Brasília: Editora Universidade de Brasília, vol. 1. 1993, p. 319 - 329.

BOWE, R., BALL, S. J., GOLD, A. Reforming Education and Changing Schools: case studies in policy sociology. London: Routledge.BALL, S. J.; BOWE, R.; GOLD, A. Reforming education \& changing school: case studies in policy sociology. London - New York: Routledge, 1992.

Presidência da República. Decreto no 6.094 de abril de 2007. Dispõe da implementação do Plano de Metas Compromisso Todos pela Educação. Brasília, 2017.

Câmara dos Deputados. Projeto Emenda à Constituição - PEC no 366 - Dá nova redação ao inciso IV e acrescenta parágrafo ao art. 206 da Constituição Federal. Brasília, 2017.

Ministério da Educação - MEC. Base Nacional Comum Curricular - BNCC. Brasília, 2017.

BURNIER, S. L. Pedagogia das competências: conteúdos e métodos. Boletim Técnico Informativo Senac, 2001.

ESQUINSANI, R. S. S. Performatividade e educação: a política das avaliações em larga escala e a apropriação da mídia. Práxis Educativa, v. 5 n. 2, 2010.

HARVEY, D. Breve historia del neoliberalismo. Madrir: Ediciones Akal, 2005.

O neoliberalismo: história e implicações. 5. ed. São Paulo: Edições Loyola, 2014.

HATTGE, M. D. Performatividade e inclusão no movimento Todos pela educação. 2014. 182 p. Tese (doutorado). Programa de Pós-Graduação em Educação, Universidade do Vale do Rio dos Sinos. São Leopoldo, RS, 2014.

KENJI, A. Kroton Educacional: 'Em termos de educação pública nunca experimentamos um inimigo com uma força social tão concentrada como esse'. Revista IHU - on-line, 30 de abril de 2018. Disponível em: $<$ http://www.ihu.unisinos.br/78-noticias/578444-kroton-educacional-em-termos-de-educacao-publicanunca-experimentamos-um-inimig o-com-uma-forca-social-tao-concentrada-como-esse>.

FAIRCLOUGH, N. Discurso e mudança social. Brasília: Universidade de Brasília. 2001.

Analysing discourse: textual analysis for social research. New York: Routledge, 2003.

FREITAS, L. C. A reforma empresarial da educação: nova direita, velhas ideias. São Paulo: Expressão Popular, 2018.

FUNDAÇÃO LEMANN. Annual Report 2016. Fundação Lemann, 2016. Disponível em: < https://fundacaolemann.org.br/materiais/relatorio-anual-2016>.

LEITE, M. S. Performatividade: inscrições, contextos, disseminações. Práxis Educativa, v. 9, n. 1, 2014. 
LOPES, A. C.; CUNHA, E. V. R.; COSTA, H. H. C. Da recontextualização à tradução: investigando políticas de currículo. Currículo sem Fronteiras, v. 13, n. 3, 2013.

LOPES, A. C.; LÓPEZ, S. B. A performatividade nas políticas de currículo: o caso do ENEM. Educação em Revista, v. 26, n. 1, 2010.

MACEDO, E. Como a diferença passa do centro à margem nos currículos: o exemplo dos PCN. Educação e Sociedade, Campinas, v. 30, n. 106, 2009.

Base Nacional Comum para Currículos: direitos de aprendizagem e desenvolvimento para quem? Educação e sociedade, v. 36, p. 891-908, 2015.

MACLEAN, N. Democracy in chains: the history of the radical right's stealth plan for América. New York: Viking, 2017.

MAGUIRE, M.; BALL, S. Discursos da reforma educacional no Reino Unido e nos Estados Unidos e o trabalho dos professores. In: BALL, S.; MAINARDES, J. (Org.). Políticas Educacionais: questões e dilemas. São Paulo: Cortez, 2011.

MAINARDES, J. Abordagem do Ciclo de Políticas: uma contribuição para a análise de políticas educacionais. Educ. Soc. Campinas, vol. 27, n. 94, p. 47-69, jan./abr. 2006

MARTINS, A.S. A educação básica no século XXI: o projeto do organismo “Todos pela Educação". Práxis Educativa, Ponta Grossa, v. 4, n. 1, p. 21-28, jan./jun. 2009.

Todos pela educação? Como os empresários estão determinando a política educacional brasileira. Rio de Janeiro: Lamparina, 2016.

MIRANDA, E. Educação científica e cultura política democrática: um estudo sobre o processo de recontextualização de elementos de formação política na prática do ensino de Ciências nas séries iniciais. 2019. Tese (Doutorado) - Instituto NUTES de Educação em Ciências e Saúde, Universidade Federal do Rio de Janeiro, Rio de Janeiro, 2019.

MOREIRA, A. F. A cultura da performatividade e a avaliação da Pós-graduação em educação no Brasil. Educação em Revista, Belo Horizonte, v. 25, n. 3, 2009.

NOVA ESCOLA. Base Nacional: as mudanças começam agora. v. 32, no 309, fevereiro de 2018.

OLIVEIRA, A.; LOPES, A. C. A abordagem do ciclo de políticas: uma leitura pela teoria do discurso. Cadernos de Educação, n. 38, 2011.

PACHECO, J. A.; PESTANA, T. Globalização, aprendizagem e trabalho docente: análise das culturas de performatividade. Educação, v. 37, n. 1, 2014.

PERRENOUD, P. Construir as competências desde a escola. São Paulo: Artmed, 2009.

PERONI, V.; CAETANO, M. R.; LIMA, P. Reformas educacionais de hoje: as implicações para a democracia. Revista Retratos da Escola, Brasília, v. 11, n. 21, 2017.

PERONI, V.; SCHEIBE, L. Privatização da e na educação: projetos societários em disputa. Revista Retratos da Escola, Brasília, v. 11, n. 21, 2017.

RESENDE, V. M.; RAMALHO, V. Análise Crítica do discurso. 2a ed. São Paulo: Contexto, 2017.

SEN, A. Sobre Ética e Economia. ed. Companhia das Letras, São Paulo, 2012.

SHIROMA, E. O. Networks in action: new actors and practices in education policy in Brazil. Journal of Education Policy, v. 29, n. 3, 2014.

SILVA JÚNIOR, J. R. Reformas educacionais, reconversão produtiva e a constituição de um novo sujeito. In: GENTILI, P.; FRIGOTTO, G. A cidadania negada: políticas de exclusão na educação e no trabalho. São Paulo: Cortez, CLACSO, 2002.

TEIXEIRA, T. Os Think Tanks e sua influência na política externa dos EUA: a arte de pensar o impensável. Rio de Janeiro: Revan, 2007. 
VERGER, A.; STEINER-KHAMSI, G.; LUBIENSKI, C. The emerging global education industry: analysing market-making in education through market sociology. Globalisation, Societies and Education, v. 15, n. 3, 2017.

VERGER, A.; NOVELLI, M.; ALTINYELKEN, H. K. Global Education Policy and International Development: a revisited introduction. In: VERGER, A.; NOVELLI, M.; ALTINYELKEN, H. K. Global Education Policy and International Development: new agendas, issues and policies. 2. ed. London: Bloomsbury, 2018.

\section{Correspondência}

Edgar Miranda: É Doutor e mestre em Educação em Ciências e Saúde pelo Instituto NUTES de Educação em Ciências e Saúde da Universidade Federal do Rio de Janeiro - UFRJ. Professor do Ensino Básico, Técnico e Tecnológico do Colégio Pedro II. Coordenador do Grupo de Estudos, Pesquisa e Extensão em Educação e Sociedade - GEPES.

E-mail: edgar.miranda620@gmail.com

Rita Vilanova: É Doutora em Educação pela Pontifícia Universidade Católica do Rio de Janeiro (2011), Mestrado em Educação em Ciências e Saúde pela Universidade Federal do Rio de Janeiro (2007). Atualmente é Professora Adjunta IV da Universidade Federal do Rio de Janeiro, no Laboratório de Linguagens e Mediações do Instituto NUTES de Educação em Ciências e Saúde. Atua no Programa de Pós-graduação Educação em Ciências e Saúde da UFRJ e coordena o Programa Articulado de Extensão Complexo de Formação de Profissionais da Educação Básica.

E-mail: vilanova.rita@gmail.com

Texto publicado em Currículo sem Fronteiras com autorização dos autores 